\title{
Pinpointing of cysteine oxidation sites in vivo by high-resolution proteomics reveals mechanism of redox-dependent inhibition of STING
}

Authors: Natalia Zamorano Cuervo ${ }^{1}$, Audray Fortin ${ }^{1}$, Elise Caron ${ }^{1}$, Stéfany Chartier $^{1}$ and Nathalie Grandvaux ${ }^{1,2 *}$

\author{
Affiliations: \\ ${ }^{1}$ CRCHUM - Centre Hospitalier de l'Université de Montréal, 900 rue Saint Denis, Montréal, H2X \\ 0A9, Québec, Canada \\ 2 Department of Biochemistry and Molecular Medicine, Faculty of Medicine, Universite de \\ Montréal, Montréal, H3C 3J7, Québec, Canada* \\ *Corresponding author: nathalie.grandvaux@ umontreal.ca; Tel.: (+1) 514-890-8000 ext. 35292
}

\section{Brief summary of the main results.}

The function of proteins is regulated by post-translational modifications, among which reversible oxidation of Cys recently emerged as a key component. Comprehension of redox regulation of cellular responses requires identification of specific oxidation sites in vivo. Using a bioswitch method to specifically label Cys subjected to reversible oxidation coupled to mass spectrometry, we identified thousands of novel oxidation sites. Many are relevant to virus-host interaction pathways. Here, we focused on the oxidation of STING, an adaptor critical for activating the innate immune type I interferon pathway engaged upon cytosolic DNA sensing. Molecular studies led us to establish a new model in which STING Cys ${ }^{148}$ is oxidized at basal levels, while $\mathrm{Cys}^{206}$ oxidation is induced by oxidative stress and ligand binding. We show that oxidation of $\mathrm{Cys}^{206}$ has an inhibitory function to prevent STING hyperactivation. This study provides ground for novel research avenues aimed at designing therapeutics that target this pathway.

\begin{abstract}
Protein function is regulated by post-translational modifications, among which reversible oxidation of Cys (Cys ox-PTM) emerged as a key regulatory mechanism of cellular responses. The redox regulation of virus-host interactions is well documented, but in most cases, proteins subjected to Cys ox-PTM remain unknown. The identification of Cys ox-PTM sites in vivo is essential to underpin our understanding of the mechanisms of the redox regulation. In this study, we present a proteome-wide identification of reversible Cys ox-PTM sites in vivo during stimulation by oxidants using a maleimide-based bioswitch method coupled to mass spectrometry. We identified 2720 unique Cys ox-PTM sites encompassing 1473 proteins with distinct abundance, location and functions. Label-free quantification (LFQ)-based analysis revealed the enrichment of ox-PTM in numerous pathways, many relevant to virus-host interaction. Here, we focused on the oxidation of STING, the central adaptor of the innate immune type I interferon
\end{abstract}


pathway induced upon detection of cytosolic DNA. We provide the first in vivo demonstration of reversible oxidation of Cys ${ }^{148}$ and $\mathrm{Cys}^{206}$ of STING. Molecular analyses led us to establish a new model in which Cys ${ }^{148}$ oxidation is constitutive, while Cys ${ }^{206}$ oxidation is inducible by oxidative stress or by the natural ligand 2'3'-cGAMP. We show that oxidation of Cys ${ }^{206}$ has an inhibitory function to prevent STING hyperactivation through the constraint of a conformational change associated with the formation of inactive polymers containing intermolecular disulfide bonds. This provides new ground for the design of therapies targeting STING relevant to autoinflammatory disorders, immunotherapies and vaccines.

Keywords: STING, oxidation, redox, antiviral, inflammation, cancer, autoimmunity, cGAS, proteomics, Cysteine.

\section{Introduction}

Changes of redox status take place during various cellular processes, including virus infections. While chronically elevated levels of reactiv e oxygen species (ROS) might be associated with oxidative damage, local changes in ROS levels act as redox switches regulating cellular signalling. Increased ROS levels has been documented during various infections by DNA viruses, such as Epstein-Barr virus (EBV) and Kaposi's sarcoma associated herpesvirus (KSHV), and RNA viruses, including hepatitis C virus (HCV), respiratory syncytial virus (RSV), influenza virus (IAV) and human immunodeficiency virus (HIV) (1-6). ROS regulate various aspects of virushost interactions, including virus replication, host defense and pathogenesis (5). Although redoxsensitive virus-induced pathways have started to be identified, such as those leading to Nuclear factorkappa-light-chain-enhancer of activ ated B cells (NF- $\mathrm{B}$ ), Interferon regulatory factor(IRF)3 or Nuclear factor erythroid 2-related factor 2 (Nrf2) activation, the exact cellular targets of ROS remain poorly characterized $(1,2,5)$.

ROS act as second messengers in cellular signaling through reversible oxidative posttranslational modifications of cysteine residues (Cys ox -PTMs) that allow modulation of protein structure, interaction with protein partners and ligand, localization and activity (7-9). Reversible Cys ox-PTMs consist of a variety of modifications, the most widely studied being S-sulfenylation (Cys-SOH), S-glutathionylation (Cys-SSG) and disulfide (S-S) (7). Iodoacetamide- or maleimide (Mal)-based bioswitch methods, allowing labeling of oxidized Cys independently of the type of reversible oxidation, coupled to immunoblot or mass spectrometry (MS) have dramatically evolved and made it possible to identify numerous proteins subjected to redox regulation in vivo (10-14). However, identification of the corresponding Cys residues subjected to ox-PTM by MS has proven to be challenging and consequently, except in the case of very abundant or highly reactive redox proteins, most often relies on the analysis of the recombinant protein oxidized in vitro $(7,12,13,15,16,17,18-21)$.

In our quest to identify novel redox regulated proteins involved in virus-host interaction, our goal was to perform proteome wide identification of in vivo Cys ox-PTM sites upon oxidants stimulation. For this purpose, we used a proven bioswitch method based on the modification of reversibly oxidized Cys with a molecule of Mal-(Polyethylene glycol)2-Biotin (Mal-PEG 2 -Bio) $(11,22)$ followed by an In-solution trypsinization with Peptide Extraction (InsPEx) workflow for identification of labeled peptides by Liquid Chromatography-Tandem Mass Spectrometry (LCMS/MS). Using this strategy, we successfully identified 2720 unique Cys ox-PTM sites corresponding to 1473 proteins with distinct abundance, localization and functions. Label-free 
quantification (LFQ)-based analysis pinpointed enrichment of reversible Cys ox-PTMs in numerous functional pathways, including many relevant to virus-host interaction.

Here, we focused on the Cys ox-PTMs of STING, also known as TMEM173, ERIS, MITA and MPYS (23-26), the central adaptor and signal relay in the interferon (IFN) pathway dependent on cyclic GMP-AMP synthase (cGAS) (27-32). The main function of cGAS-mediated STING activation is innate immune defense when detecting DNA from pathogens, including DNA viruses (33). Increasing evidence also support paradoxical roles of the cGAS-STING pathway in tumor immunity and proliferation of tumor cells (34-36). STING must be strictly regulated because constitutive activation leads to autoimmune and autoinflammatory disorders (37-39). Double strand DNA (dsDNA) released into the cytoplasm are recognized by cGAS leading to the production of the 2'3'-cGAMP second messenger that has high-affinity for STING located at the membrane of the endoplasmic reticulum (ER). Binding of 2' 3'-cGAMP induces a conformational change and the translocation to a perinuclear compartment $(23,25,29,40)$, where it colocalizes and interacts with the TBK1 kinase to ultimately activate the transcription factor IRF3 to induce type I IFNs and other cytokines $(23,41-43)$.

We demonstrate in vivo reversible oxidation of Cys ${ }^{148}$ and Cys ${ }^{206}$ of STING. Cys ${ }^{148}$ oxidation status is independent of cell treatment, while induction of oxidative stress or stimulation with the natural STING ligand 2'3' -cGAMP is required to trigger reversible oxidation of Cys ${ }^{206}$. Further mutational analy ses combined to in silico molecular modeling allowed us to establish a novel model in which $\mathrm{Cys}^{206}$ oxidation provokes a conformational change associated with formation of inactive diS-containing polymers to prevent STING hyperactivation. This study paves the way to the design of novel STING agonists or antagonists for treatment of autoinflammatory disorders, immunotherapies and vaccines.

\section{Results}

Proteome-wide identification of Cys ox-PTM sites in basal and oxidant-stimulated U937 cells.

Accurate identification of sites of Cys ox-PTM in vivo in mammalian cells in a proteomewide fashion by Mass spectrometry (MS) has proved to be challenging due to lack of sensitivity $(14,44)$. Here, we used a proven bioswitch method with a Maleimide-(Polyethylene Glycol)2Biotin (Mal-PEG 2 -Bio) probe to specifically label Cys subjected to reversible ox-PTM independently of the oxidation type (Fig. 1A) $(11,17,45)$. In pilot experiments, Mal-PEG ${ }_{2}$-Biolabeled proteins generated from cells stimulated for $20 \mathrm{~min}$ with $0.5 \mathrm{mM}$ diamide, a thiol-oxidizing agent (46), were subjected to a standard procedure of NeutrAvidin-mediated pull-down (47), followed by in-gel trypsinization before analysis by LC-MS/MS (In-gel trypsinization workflow, fig. S1A-B). The fragmentation spectra of the detected peptides were searched on Mascot and Scaffold for peptides containing Cys with a mass shift of 525.23 Da corresponding to the molecular weight (MW) of the Mal-PEG ${ }_{2}$-Bio moiety (Fig. 1C). While this strategy permitted identification of proteins subjected to Cys ox-PTM sites, the ratio of peptides containing at least one biotinylated Cys against the total number of peptides was as low as $0.5 \%$ (fig. S1C). Moreover, assignment of peptides to human proteins using the same programs revealed that they corresponded only to wellknown redox proteins, such as thioredoxins (Trxs), peroxiredoxins (Prxs) and glutathione peroxidases (GPxs) $(48,49)$ (Data File S1). As an attempt to reach a better sensitivity in the detection of Cys ox-PTM sites, a modified workflow was used. Mal-PEG ${ }_{2}$-Bio-labelled proteins 
were immediately subjected to in-solution trypsin digestion, followed by a solid-phase extraction step using reverse-phase tC18 SepPak liquid-solid-phase cartridge before NeutrAvidin pull-down and elution in $8 \mathrm{M}$ guanidine/ $\mathrm{HCl} \mathrm{pH} 1.5$ (In-solution trypsinization with Peptide Extraction (InsPEx) workflow, Fig. 1B). Using this InsPEx workflow, Mal-PEG 2 -Bio-modified peptides were found highly enriched to a ratio over total peptides of $83 \%$ (fig. S1C and Data File S2). Importantly, the identified peptides containing at least one biotinylated Cys encompassed proteins with a diverse range of activities and localization (Data File S2).

Based on these pilot experiments, the InsPEx workflow was pursued to identify novel proteins involved in virus-host interaction susceptible to reversible Cys oxidation in vivo. U937 cells unstimulated (basal conditions) or treated with $0.5 \mathrm{mM}$ diamide or $100 \mu \mathrm{M}$ hypochlorous acid $(\mathrm{HOCl})$, an oxidant produced in vivo during infections as a result of neutrophils activity (50), for

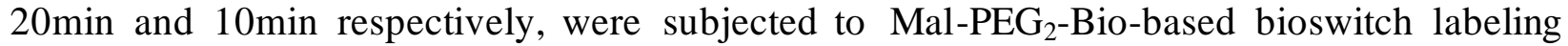
followed by the InsPEx workflow. Peptides extracted from triplicate independent experiments were analyzed by LC-MS/MS. Results of triplicates were combined for identification of the Mal$\mathrm{PEG}_{2}$-Bio-labeled peptides. Overall, this strategy led to the identification of 2699 unique peptides containing 2720 biotinylated Cys residues. Amongst these, $1489 \mathrm{Cys}$ ox -PTM sites belonging to 841 different proteins were found at basal levels; 1655 Cys ox-PTMs corresponding to 980 proteins were identified in cells stimulated with diamide; 1818Cys ox-PTMs encompassing 1090 proteins were found in HOCl-stimulated cells (Fig. 1D and Data File S3).

Identification of pathways related to virus-host interaction enriched in proteins subjected to Cys ox-PTMs.

To get insight into the functional implication of the proteins found to contain Cys ox-PTMs under basal or oxidative stress conditions, a Label Free Quantification (LFQ) method was applied considering only Mal-PEG 2 -Bio-labeled Cys identified in at least two out of the three independent replicates per condition to eliminate possible "false positive" hits $(51,52)$. The accuracy of our approach was first validated by the identification of Cys ox-PTM sites previously documented to be oxidized in vitro or in vivo (fig. S2).

Next, Gene Ontology (GO) enrichment analysis was performed using the BiNGO plugin into Cytoscape $(53,54)$. To look for Cys ox-PTMs occurring exclusively at basal levels or in oxidative stress condition independently of the type of oxidant, diamide and $\mathrm{HOCl}$ conditions were pooled in the analysis. A total of 74 biological processes (BP) were enriched in basal state and 212 in oxidant-stimulated cells (see Data File S4 for a complete list). Several enriched BPs were relevant to host-virus interactions (Fig. 2A): in unstimulated cells, they include translation related processes (translation elongation and translation), and several processes associated with the host immune defense (immune effector process, immunoglobulin biosynthetic process, leukocyte mediated cytotoxicity, immune system process); upon oxidant stimulation, translation and immune related processes (leukocyte activation, immune system process) were also enriched, in ad dition to BPs related to intracellular protein localization (intracellular transport, establishment of protein localization, protein transport and nuclear transport). Further identification of functional clusters amongst these enriched BPs was performed through network community analyses using the fast greedy GLay algorithm (fig. S3A). This revealed the prevalence of functional clusters related to immune functions (mediated cytotoxic immunity and antigen symbiont stress) at basal levels and to cell transport, translation frameshifting termination, regulation of phosphorylation and immunity in cells stimulated with oxidants. Fourteen molecular functions (MF) were found significantly enriched in basal conditions and 54 upon oxidants stimulation (see Data File $\mathbf{S 4}$ for 
a complete list). One of the most enriched MF, both at basal levels and under conditions of oxidative stress, is related to the catalytic functions of proteins (Fig. 2B). Further analysis using the GLay algorithm revealed association of these functions into 4 clusters, i.e. peptidase isomerase activity, binding of NAD, structural molecule activity and immune system (MHC class protein), at basal levels (fig. S3B). Upon oxidative stress, functional clusters associated with catalytic activities were related to kinase and phosphatase activities (Ser/Thr activity, protein phosphotyrosine binding and adenyl nucleotide ribonucleotide) (fig. S3B).

Analysis of the cellular component (CC) identified 30 and 74 GO terms enriched under basal and oxidants stimulation conditions, respectively (see Data File S4 for full list). In both conditions, the most enriched compartment corresponds to the cytoplasm (Data File S4). At basal levels, terms associated with vesicles/vacuoles (lytic vacuole, lysosome, vacuole and cytoplasmic vesicle), grouped into the functional cluster membrane-bounded vesicle vacuole were highly enriched, as were ER-related terms (ER, ER lumen and ER part) (Fig. 2C and fig. S3C). In contrast, following oxidant treatment, the enriched CC terms were c orresponded to clusters related to the nucleus (nuclear periphery spliceosome, nucleoplasmic shuttling complex) and mitochondria (mitochondrial part nucleoid) (Fig. 2C and fig. S3C).

To further characterize the signaling pathways related to host-virus interaction subjected to redox regulation, Kyoto Encyclopedia of Genes and Genomes (KEGG) pathway analyses were performed using the ClueGO plugin (55). At basal levels, 16 KEGG terms were significantly enriched compared to 26 in cells subjected to oxidant treatments (see Data File $\mathbf{S 5}$ for full list and fig. S4 for full map). Amongst these enriched pathways, several are relevant to virus-host interaction (Fig. 2D-F): in unstimulated cells, pathways related to the host defense system, such as those associated with lysosomes, phagosomes, antigen processing and presentation and complement and coagulation cascades (Fig. 2D and E); in oxidant-treated cells, pathways related to the immune system, including phagosome, $\mathrm{Fc}$ gamma R-mediated phagocytosis, antigen processing and presentation, NOD-like receptor signaling pathway, RNA-associated pathways (RNA transport, mRNA surveillance pathway) and specific virus infections-related pathways (HIV1 infection, Influenza A, Herpes simplex infection) (Fig. 2D and F). Together, our data revealed that in a cellular context, hundreds of proteins involved in virus-host interaction undergo reversible Cys ox-PTM, making it possible to envisage new regulatory mechanisms.

STING Cys ${ }^{206}$ undergoes oxidized reversible ox-PTM upon oxidative stress and 2'3'-cGAMP stimulation.

Amongst the Cys ox-PTM-containing proteins related to host-virus interaction, identified in the KEGG pathways enriched in cells subjected to oxidant, is the DNA virus antiviral signaling adaptor STING encoded by TMEM173 (Fig. 2F). Oxidation of Cys ${ }^{206}$ was detected in HOClstimulated cells (Fig. 3B and Datafile S3). Further analysis of our data set also revealed oxidation of $\mathrm{Cys}^{148}$, but the modification was detected in both the basal condition and following oxidant treatment (Fig. 3A-B and Datafile S3).

STING is activated through the docking of 2'3'-cGAMP generated upon DNA recognition by cGAS $(27,29,31,32)$. Therefore, we next sought to determine whether Cys ${ }^{206}$ also undergoes reversible oxidation following stimulation by 2'3'-cGAMP. U937 cells were first treated with 2'3'-cGAMPfor various times and analyzed by immunoblot. Phosphorylation of STING on Ser ${ }^{366}$, a marker of STING activation (56), and of the downstream effector kinase TBK1 on Ser ${ }^{172}$ (57), were detected after 15min of 2'3'-cGAMP stimulation (Fig. 3C). Previous studies have reported 
that stimulation by 2'3'-cGAMP leads to disulfide (diS) bond-dependent form of STING dimer and high molecular weight (HMW) aggregates $(58,59)$. Analysis of whole cell extracts (WCE) by non-reducing SDS-PAGE confirmed the formation of intermolecular diS-containing dimeric form of STING, migrating at about $74 \mathrm{kDa}$ after $15 \mathrm{~min}$ of stimulation (Fig. 3D). It is noteworthy, that additional intermolecular diS-containing oligomeric species of higher MW were also detected during the course of 2'3'-cGAMP stimulation (Fig. 3D). Ser ${ }^{366}$ phosphorylation of STING was detected in the diS-containing dimeric form (Fig. 3D). Resolution of WCE by SDD-AGE also confirmed the formation of HMW aggregates starting at $15 \mathrm{~min}$ of 2'3'-cGAMP stimulation (Fig. 3E). Based on these observations, U937 cells subjected to stimulation with 2'3'-cGAMP for 30min and the corresponding control cells were subjected to $\mathrm{Mal}_{-} \mathrm{PEG}_{2}-\mathrm{Bio}$-based bioswitch labeling followed by the InsPEx workflow to detect reversible Cys ox-PTMs (Fig. 1A). Oxidation of Cys 206 was detected in 2'3'-cGAMP-stimulated cells, but not in control cells (Fig. 3F and fig. S5). Overall, our data unveils the reversible oxidation of Cys ${ }^{148}$ and Cys ${ }^{206}$ of STING. While Cys ${ }^{148}$ oxidation status is independent of cell treatment, oxidative stress induced by $\mathrm{HOCl}$ and stimulation with the natural STING ligand 2'3'-cGAMP trigger reversible oxidation of Cys ${ }^{206}$.

Cys ${ }^{206}$ oxidation dampens STING activation.

The importance of Cys ${ }^{148}$ oxidation in the capacity of STING to be activated by 2'3'cGAMP was recently documented $(60,61)$. Hence, in this study we focused on elucidating the role of $\mathrm{Cys}^{206}$ oxidation. According to the available tridimensional structures of human STING dimer bound to 2'3'-cGAMP (29, 61-65), Cys ${ }^{206}$ lies in the 2'3'-cGAMP binding pocket (Fig. 4A-C). To start investigating the impact of $\mathrm{Cys}^{206}$ oxidation, we used the PyTMs plugin in PyMOL software to perform in silico molecular assessment of the steric van-der-Waals (vdW) hindrance in the structure due to Cys ${ }^{206}$ modification by sulfenylation $(\mathrm{SOH})$. Predicted steric structural strains (vdW clashes, (66)) were observed within the dimer interface and between Cys ${ }^{206}$ and $\operatorname{Arg}^{284}$ (Fig. 4B and C) indicating that a change in conformation must take place after oxidative modification of $\mathrm{Cys}^{206}$.

To further delineate the role of Cys ${ }^{206}$ reversible ox-PTM in the regulation of STING function, we tested the impact of Cys ${ }^{206}$ mutation into Ser (STING-C206S) (Fig. 4D), which suppresses its capacity to be oxidized, on STING-mediated signaling. First, confocal indirect immunofluorescence analysis revealed that Flag-tagged-STING WT and -STING-C206S exhibit similar localization at basal levels and translocation to perinuclear punctate structures upon 2'3'cGAMP stimulation (Fig. 4D-E). Next, the activity of STING WT and STING-C206S was measured through their capacity to transactivate the IFN $\beta$ promoter using a luciferase-based reporter assay at basal levels and upon stimulation with 2'3' cGAMP. As expected, the activity of STING WT was significantly enhanced by 2'3'-cGAMP in a dose-dependent manner (Fig. 4F). The STING-C206S mutant strongly induced the IFN $\beta$ promoter in the absence of ligand compared to STING WT (29.5 fold compared to 8.1 fold, Fig. 4F). STING-C206S mutant activity was highly increased by 2'3'-cGAMP compared to STING WT (70.7 fold compared to 19.2 fold, Fig 4F). Altogether, our data suggests that modification of Cys ${ }^{206}$ plays an inhibitory function and support a model in which Cys ${ }^{206}$ oxidation would prevent STING hyperactivation.

Next, we studied the impact of $\mathrm{HOCl}$ on STING in the absence or presence of stimulation by 2'3'-cGAMP. For this purpose, cells expressing Flag-tagged-STING WT or - STING-C206S were stimulated or not with 2'3'-cGAMP for $1 \mathrm{~h}$ before further treatment with $\mathrm{HOCl}$. First, the capacity of STING WT and STING-C206S to activate the IFN $\beta$ promoter luciferase reporter was evaluated. Our results indicate that $\mathrm{HOCl}$ inhibits 2'3'-cGAMP-induced activity of STING WT 
by $44 \%$, while inhibition of C206S activity was limited to 22\% (Fig. 5A). In the absence of 2'3'cGAMP stimulation, $\mathrm{HOCl}$ diminished STING WT activity by $40 \%$, whereas no significant inhibition of STING-C206S mutant was observed (Fig. 5B). These observations confirmed that oxidative stress inhibits STING activation in a Cys ${ }^{206}$-dependent manner. In order to gain further insight into the mechanism by which Cys206 oxidation inhibits STING activity, phosphorylation of STING on Ser $^{366}$ was analyzed by immunoblot. Stimulation by 2'3'-cGAMP led to hyperphosphorylation of the STING-C206S mutant compared to STING WT. STING WT phosphorylation on $\mathrm{Ser}^{366}$ triggered by 2 '3'-cGAMP was fully abrogated by $\mathrm{HOCl}$ treatment, while induction of STING-C206S phosphorylation was only slightly decreased (Fig. 5C). In the absence of 2'3'-cGAMP, HOCl did not alter basal STING WT phosphorylation, and only slightly diminished STING-C206S mutant phosphorylation (Fig. 5D). Altogether, these findings point to a role of $\mathrm{Cys}^{206}$ oxidation in the prevention of STING hyperactivation through the inhibition of STING Ser ${ }^{366}$ phosphorylation.

We next assessed the state of polymerization of STING WT vs STING-C206S by nonreducing SDS-PAGE and SDD-AGE. Cells expressing Flag-tagged-STING WT or - STINGC206S were stimulated or not with 2'3'-cGAMP for $1 \mathrm{~h}$ before further treatment with $\mathrm{HOCl}$ or the corresponding control medium for the indicated times (Fig. 5E). As expected based on observations made on endogenous STING (Fig.3C-E), 2'3'-cGAMP stimulation triggered STING WT to form transient diS-containing oligomers of various sizes (Fig. 5E, lanes 4-5 compared to lane 2, middle panel) together with an accumulation of HMW aggregates (Fig. 5E, lanes 4-5 compared to lane 2, lower panel). The different diS-containing species were not detected with the STING C206S mutant and the HMW aggregates were strongly reduced (Fig. 5E, lanes 10-11 compared to lanes 4-5, middle and lower panel). Surprisingly, while $\mathrm{HOCl}$ alone did not activate, but rather inhibited STING, as measured by IFN $\beta$ luciferase reporter assay and Ser ${ }^{366}$ phosphorylation (Fig. 5B and D), it induced an accumulation of diS-containing dimeric and oligomeric species associated with transient formation of aggregates (Fig. 5E, lanes 6-7 compared to lane 2 , middle and lower panel). It is noteworthy that the diS-containing species differ from those observed in response to 2'3'-cGAMP in that they are partially resistant to denaturing and reducing treatments (Fig. 5E, lanes 6-7 compared to lanes 4-5, upper panel). The profile was similar with STING-C206S although at a much-reduced level (Fig. 5E, lanes 1213 compared to lanes 6-7). Finally, when cells were stimulated with 2'3'-cGAMP before HOCl treatment, STING WT and STING-C206S behaved similarly as with $\mathrm{HOCl}$ alone (Fig. 5E, lanes 8-9 compared to lanes 6-7 and lanes 14-15 compared to lanes 12-13). Overall, our data point to an inhibitory role of Cys ${ }^{206}$ ox-PTM associated with inhibition of Ser $^{366}$ phosphorylation and formation of inactive diS-containing polymers.

\section{Discussion}

The understanding of cell signaling regulation by redox processes has largely benefitted from the recent development of labeling techniques aimed at identifying protein subjected to reversible Cys ox-PTMs $(7,15)$. Although these techniques have allowed identification of numerous human proteins undergoing Cys ox-PTMs in vivo, the report of specific oxidation sites by MS is very often limited to proteins highly abundant and/or highly susceptible to oxidation (13, 14, 67). In most cases, identification of the oxidized residue by MS relied on the production of recombinant proteins and in vitro oxidation (19-21). In the present study, we successfully used Mal-PEG 2 -Bio-based labeling coupled to InsPEx workflow to identify novel Cys ox-PTM sites in 
vivo by LC-MS/MS (Fig. 1). Overall, we identified 2720 unique Cys ox-PTM sites encompassing 1473 proteins in U937 cells either unstimulated or subjected to treatment with diamide or $\mathrm{HOCl}$ (Fig. 1D and Data File S3).

The broad map of the identified proteins subjected to reversible Cys ox-PTM in vivo encompasses proteins with various activities, including those important for cellular signaling such as kinases, phosphatases, isomerases, transporters and receptors (Fig. 2 and Data File S4). Additionally, proteins subjected to reversible Cys ox-PTM exhibited various subcellular localizations, including cytoplasm, vacuoles/lysosomes compartments, ER, mitochondria and the nucleus (Fig. 2). Of interest to us, we identified numerou s proteins potentially involved in virushost interaction. Several BPs enriched in proteins harboring Cys ox-PTM were related to translation and intracellular localization regulation (intracellular transport, establishment of protein localization, protein transport and nuclear transport) (Fig. 2). Functional clusters analysis highlighted the importance of translation frameshifting termination, and transport multivesicular localization. The translational and intracellular transport functions found regulated by oxidative stress are relevant to host-virus interaction because of their involvement in cell signaling regulation, but also because they are key for proper virus replication and assembly (68). KEGG pathways analysis revealed selective enrichment of Cys ox-PTMs in RNA transport pathway, which include several components of the nuclear pore function, namely nucleoporins and exportins (Fig. 2F, fig. S4B and Data File S5). Transport in and out of the nucleus is particularly important for viruses with steps of their replication cycle occurring in the nucleus, such as influenza virus $(69,70)$. Additionally, numerous viruses hijack the nuclear pore through NUPs to regulate trafficking of viral proteins, genomes and even capsids into and out of the nucleus, thus promoting their replication (71). Previous reports have shown that oxidative stress regulates export from the nucleus through post-translational modifications of NUPs $(72,73)$. The reversible Cys ox-PTMs sites in NUPs and exportins identified in this study likely represents novel regula tory mechanisms of nuclear transport. Several BPs enriched in proteins harboring Cys ox-PTMs were also related to the immune response (immune system processes and leukocyte activation) (Fig. 2). For instance, we identified several novel Cys ox-PTM sites of components of the major histocompatibility complex I (MHC-I) upon oxidant treatment: HLA-A Cys188, Cys227, and Cys363; HLA-C Cys188 and Cys227; HLA-DRA Cys188. Above all, analyzes of the KEGG pathways revealed numerous proteins specifically involved in the interaction of the host with RNA (influenza) and DNA viruses (Herpes simplex and HIV) subjected to Cys ox-PTMs (Fig. 2F). In particular, this study provides the first direct demonstration that the adaptor STING, which is key to the IFN antiviral and proinflammatory response triggered following DNA virus sensing, is subjected to reversible Cys ox-PTMs.

Previous reports have documented contradictory evidence of redox regulation of the STING pathway. In some studies, modulation of the nuclear factor erythroid 2-related factor 2 (Nrf2), which is essential for the production of antioxidants and protection of cells against oxidative stress, decreased 2'3'-cGAMP or DNA virus-induced STING-dependent responses, suggesting a positive regulation by ROS (74-76). In contrast, ROS appear to inhibit PPAR $\mathrm{P}^{-}$ mediated activation of STING-dependent IFN expression (77). Inhibition of ectopically expressed STING activity was also observed uponinduction of ROS by the mitochondrial complex I inhibitor rotenone (60). Certainly, several reports have provided evidence pointing to a role of Cys residues in the redox regulation of STING in that they showed formation of diS-containing dimers and aggregates sensitive to reducing agents upon ligand stimulation $(58,60,61,78-80)$. However, the 
identity of Cys subjected to ox-PTM and their role remained to be elucidated.

Here, we demonstrate oxidation of Cys ${ }^{148}$ under basal conditions and upon treatment with $\mathrm{HOCl}$, while oxidation of $\mathrm{Cys}^{206}$ was inducible by $\mathrm{HOCl}$ and by the natural 2'3'-cGAMP ligand (Fig. 3 and fig. S5). Previous reports have shown that STING-C148A and-C148S mutants exhibit impaired capacity to transit to the golgi and activate the IFN $\beta$ promoter, thereby supporting that Cys $^{148}$ oxidation is necessary for STING activation $(60,61)$. Although formation of diS-bound dimer upon $\mathrm{H} 2 \mathrm{O} 2$ and 2'3'-cGAMP stimulation was also impaired, the oxidation of Cys ${ }^{148}$ was not directly demonstrated $(60,61)$. Despite the fact that none of the available human ligand-bound STING structures allows to see the linker region containing Cys ${ }^{148}$ in electronic density maps (29, $61-65,81-91)$, it was proposed that $\mathrm{Cys}^{148}$ is engaged in a ligand-inducible diS bond that stabilizes the uncrossed linker regions in the STING polymer $(60,61)$. Our data, however, argues in favor of a different model in which Cys ${ }^{148}$ oxidation is already present at basal levels. In agreement with previous reports $(60,61)$, we did not detect dimers or oligomers containing intermolecular diS at basal levels, inferring that Cys ${ }^{148}$ is not engaged in intermolecular diS bond, but rather subjected to another type of ox-PTM that remains to be identified. We evaluated the presence of intramolecular diS bond by non-reducing SDS-PAGE (fig. S6). Although our results suggest the existence of a previously unrecognized intramolecular diS in ectopically ex pressed STING, it appears to be independent of Cys ${ }^{148}$. Thus, this study adds to previous reports to support a model in which Cys ${ }^{148}$ oxidation is essential for STING activity.

The observation that the 2'3'-cGAMP stimulation of the STING-C206S mutant leads to hyperactivation of STING together with the demonstration that $\mathrm{HOCl}$ inhibits STING activity in a Cys ${ }^{206}$-dependent manner (Fig. 4F and 5A-B) support an inhibitory role of the oxidation of $\mathrm{Cys}^{206}$ induced by 2'3'-cGAMP. This inhibition is associated with decreased Ser $^{366}$ phosphorylation and formation of diS-containing polymers. Our finding that impairment of Cys ${ }^{206}$ oxidation through mutation into Ser leads to constitutive activity that is further hyperactivated in response to 2'3'-cGAMP is in agreement with a previous study reporting a patient with a gain-offunction mutation of Cys 206 ( $\mathrm{pC} 206 \mathrm{Y}$ ) associated with the STING-associated vasculopathy with onset in infancy (SAVI) type I interferonopathy (92). The gain-of-function phenotype was recapitulated by mutation of Cys ${ }^{206}$ into Phe, Leu and Ser (92). In this same study, patients with gain-of-function mutations of $\operatorname{Arg}^{281}(\mathrm{pR} 281 \mathrm{Q})$ or (pR284G) that are spatially located close to Cys $^{206}$ (Fig. 4B-C) were also identified. Arg residue are known to lower the pKa of Cys residue, thereby rendering ox-PTM possible $(93,94)$. The close proximity of $\mathrm{Cys}^{206}$ and Arg residues in the STING structure, together with the observation that $\operatorname{Arg}^{281}$ and $\operatorname{Arg}^{284}$ mutations mimic the gain-of-function observed with mutations of $\mathrm{Cys}^{206}$ that abolish ox-PTM, might suggest $\operatorname{Arg}^{281}$ and $\mathrm{Arg}^{284}$ are essential for Cys ${ }^{206}$ to be oxidized. However, further characterization of the STINGR284S mutant that recapitulates the gain-of-function phenotype, as did R284G, R284H and R284K mutations, revealed constitutive aggregation and formation of perinuclear puncta that were not further enhanced by 2'3'-cGAMP stimulation $(60,61)(92)$. This differs from our observation that STING-C206S constitutively active phenotype can by hyperactivated by 2'3'-cGAMP and is not associated with constitutive polymerization or localization in perinuclear puncta, but rather with increased phosphorylation (Fig. 4F and 5). Altogether, this argues against a role of $\mathrm{Arg}^{284}$ in Cys $^{206}$ oxidation. 
Predictions from the currently available cGAMP-bound unphosphorylated STING dimer structure do not show direct engagement of Cys 206 in diS bond. This could suggest that Cys ${ }^{206}$ is engaged in interdimer diS bond or in an interaction with a yet to be identified protein partner rather than in the formation of STING dimers. Those diS bonds would not be visible in the structures of the dimer. Alternatively, this could also suggest that $\mathrm{Cys}^{206}$ is subjected to an ox-PTM distinct from diS but critical for the latter to form between other residues that were not detectable using our MS workflow. Ultimately, the determination of the exact oxidative modification of Cys ${ }^{148}$ and $\mathrm{Cys}^{206}$ would benefit from the development of novel dynamic models of STING structure taking into account not only the binding of the ligand but also the conformational changes induced by phosphorylation and oxidation. Mean while, in silico molecular modeling of the structure of ligandbound STING containing sulfenylated $\mathrm{Cys}^{206}$ allowed us to get insight into the mechanism of STING inhibition. Based on the steric constraints imposed by the sulfenylation of Cys ${ }^{206}$ (Fig. 4 B-C), it is very likely that once oxidized, STING must undergo a change of conformation (66). Although we cannot exclude other mechanisms, it is reasonable to propose that this new conformation is not favorable for the binding of the TBK1 kinase or for TBK1 to access Ser ${ }^{366}$, thus explaining the Cy s ${ }^{206}$-dependent inhibition of 2'3'-cGAMP-induced $\mathrm{Ser}^{366}$ phosphorylation by $\mathrm{HOCl}$ (Fig. 5). In agreement with previous reports $(58,60,61,78-80)$, we observed that oxidized STING induced by 2'3'-cGAMP is associated with the formation of polymers of different sizes containing diS (Fig. 3 and 5). Here, we show that mutation of Cys ${ }^{206}$ that results in STING hyperactivation by 2'3'-cGAMP leads to a loss of these polymers. In addition, $\mathrm{HOCl}$ inhibits STING activity while triggering the formation of the diS-containing polymers in a Cys ${ }^{206}$ dependent manner (Fig. 5). Taken together these observations suggest that the diS-containing polymers induced by 2'3'-cGAMP constitute inactive STING species. We also found that oxidative stress alone is sufficient to trigger the formation of inactive diS-containing oligomers and aggregates (Fig. 5E). These species are most likely distinct from the ligand-induced oligomers previously reported to be indispensable for STING binding to TBK1 and subsequent phosphorylation $(85,88,95)$. Mutations which disrupted the formation of oligomers detected by gel filtration chromatography or native-PAGE, methods which do not assess the diS content, correlated with the inhibition of STING signaling in response to 2'3'-cGAMP $(85,95)$. These species also differ from those detected in our study in that they were found to contain phosphorylated $\operatorname{Ser}^{366}$ (95), whereas we did not detect phosphorylation of oligomers containing diS (Fig. 3D). Together, these observations support that distinct polymeric STING species that correspond to the active and inactive states can be detected after stimulation with 2'3'-cGAMP. The distinction of the state of activity cannot be determined solely with the size of the polymer, but must include the study of the content in diS dependent on Cys ${ }^{206}$.

Collectively, our data establish a novel model of STING regulation by ox-PTMs (fig. S8). First, STING Cys ${ }^{148}$ is oxidized independently of ligand binding or induction of oxidative stress. According to previous reports, this oxidation state is essential for STING to be activated by 2'3'cGAMP (61). Next, binding of 2'3'-cGAMP triggers Ser ${ }^{366}$ phosphorylation by TBK1 and activation of STING leading to expression of IFN $\beta$. Further oxidation of Cys ${ }^{206}$ in response to 2'3'-cGAMP imposes a conformational change that inhibits $\operatorname{Ser}^{366}$ phosphorylation and provokes the formation of inactive diS-containing polymers to prevent STING hyperactivation. This study paves the way to the design of novel STING agonists or antagonists for treatment of autoinflammatory disorders and development of immunotherapies and vaccines. 


\section{Materials and Methods}

\section{Cell culture}

The monocytic cell line U937 (obtained from Dr. M. Servant, Université de Montréal, Quebec, Canada) was cultured in RPMI medium (GIBCO) supplemented with $1 \%$ L-glutamine (GIBCO), $1 \%$ HEPES (GIBCO) and 10\% Fetalclone III (FCl-III, Hyclone). The A549 and human embryonic kidney (HEK) 293T cell lines (American Type Culture Collection, ATCC) were respectively grown in F12 and DMEM medium (GIBCO), both supplemented with 1\% L-glutamine and 10\% FCl-III. No antibiotics were used for cell culture. The MycoAlert Mycoplasma Detection Kit (Lonza) was used to monitor mycoplasma contamination on a regular basis.

\section{Plasmids}

The pcDNA3.1 Flag-STING plasmid, encoding for the human protein, was obtained from Dr. D. Lamarre, Université de Montréal, Montréal, Canada. The pcDNA3.1 Flag-STING-C206S construct was generated using the Quikchange Lightning Site-Directed Mutagenesis kit from Agilent (\#210518) with the following primer (Invitrogen): 5'TTGAAATTCCCTTTTTCACTCACTGCAGAGATCTCAGC-3'. Mutation and STING sequence was validated by Sanger sequencing at the Génome Québec Innovation Centre (McGill University, Montréal, QC).

\section{Plasmid transfection}

Plasmid transfection in HEK293T cells was achieved using the calcium phosphate coprecipitation method. A total of $2.5 \mu \mathrm{g}$ of DNA was transfected per 24 well for $24 \mathrm{~h}$. For A549, the TransIT-LT1 transfection reagent (Mirus) was used to transfect a total of $3 \mu \mathrm{g}$ of DNA per $35 \mathrm{~mm}$ plate of cells at a confluency of $70 \%$, with a TransIT/DNA ratio of 1:2 as per manufacturer instructions.

\section{Oxidants preparation}

Diamide (Sigma Aldrich) was prepared from a 0.5M stock solution in ddPBS (GIBCO) by dilution in DMEM without phenol red (DMEM w/o PR, GIBCO) containing 1\% L-glutamine and $2 \%$ FCI-III. Hypochlorous acid $(\mathrm{HOCl})$ was prepared by $1 / 5$ dilution of $\mathrm{NaOCl}$ solution with available chlorine 4.00-4.99\% (Sigma Aldrich) in ddH2O containing 0.1 M NaOH. The pH was adjusted to 11 with $12.1 \mathrm{M} \mathrm{HCl}$ (BioShop). HOCl concentration was quantified by measure of absorbance at $292 \mathrm{~nm}$ with a molar absorption coefficient of $350 \mathrm{M}-1 \mathrm{~cm}-1$. The final solution at the desired concentration was obtained by dilution in DMEM w/o PR supplemented with $2 \%$ FCI-III and $1 \%$ L-glutamine.

\section{Cells treatment with oxidants}

For U937 cells treatment, cells were plated at a concentration of $10^{6}$ cells $/ \mathrm{mL}$ in RPMI supplemented with 1\% L-glutamine, 1\% HEPES and 10\% FCl-III. Sixteen hours before stimulation, the medium was replaced by DMEM w/o PR containing 2\% FCI-III and $1 \%$ Lglutamine. At the time of stimulation, the medium was replaced by DMEM w/o PR containing $1 \%$ L-glutamine, $2 \%$ FCI-III and $0.5 \mathrm{mM}$ diamide or $100 \mu \mathrm{M} \mathrm{HOCl}$. Treatments were pursued for the indicated times. For HEK293T and A549 cells transfected with STING-encoding plasmids, cells were treated with $\mathrm{HOCl}$ at $100 \mu \mathrm{M}$ for the indicated times in the corresponding medium containing 2\% FCI-III and 1\% L-glutamine. Where indicated, cells were transfected with 2'3'-cGAMP as detailed below $1 \mathrm{~h}$ before $\mathrm{HOCl}$ treatment. 


\section{2'3'-cGAMP transfection}

In U937 cells, infusion of 2'3'-cGAMP (Invivogen) was carried out by digitonin permeabilization as previously described in (96). Briefly, cells at $90 \%$ confluency were incubated at $37^{\circ} \mathrm{C}$ for $30 \mathrm{~min}$ in a buffer containing $50 \mathrm{mM}$ Hepes pH 7.0, $100 \mathrm{mM} \mathrm{KCl}$ (Sigma Aldrich), $3 \mathrm{mM}$ $\mathrm{MgCl} 2$ (Sigma Aldrich), 85mM sucrose (Sigma Aldrich), 0.2\% (m/v) BSA (Sigma Aldrich), $0.1 \mathrm{mM}$ DTT, $10 \mu \mathrm{g} / \mathrm{mL}$ digitonin (Sigma Aldrich), 1mM ATP (Sigma Aldrich), 0.1mM GTP (Sigma Aldrich) with or without 2'3'-cGAMP at a final concentration of $24 \mu \mathrm{g} / \mathrm{mL}$. After 30min, the buffer was replaced with RPMI containing 10\% FCl-III, 1\% L-glutamine, 1\% HEPES. Stimulations were pursued for the indicated times. 2'3'-cGAMP transfection in HEK293T and A549 cells was achieved using the Lipofectamine 2000 transfection reagent (Invitrogen). Briefly, 2'3'-cGAMP at 8 or $24 \mu \mathrm{g} / \mathrm{mL}$ was used to transfect cells at $90 \%$ confluency using a Lipofectamine ratio of $1: 1$ in medium containing $2 \%$ FCl-III. For transfections longer than $6 \mathrm{~h}$, medium was replaced by fresh medium supplemented with $2 \%$ FCl-III.

Bioswitch labeling of Cys ox-PTMs

Unless otherwise stated, all steps were performed on ice and in the dark. At time of harvesting, cells were immediately transferred to pre-chilled tubes and washed in cold ddPBS before trichloroacetic acid (TCA, Sigma Aldrich)/acetone (Fisher chemical) precipitation (11). After TCA/acetone addition, samples were sonicated (3x15 pulses, 70\%, UP50H sonicator, Hielscher) with rounds on ice. Samples were stored at $-80^{\circ} \mathrm{C}$ for at least $2 \mathrm{~h}$ before further processing. The bioswitch labeling procedure was performed according to the protocols described in $(11,45)$ with modifications using N-ethylmaleimide (NEM, Sigma Aldrich) to alkylate the reduced thiols, tris(2-carboxyethyl)phosphine (TCEP, EMD Millipore Sigma) to reduce the oxidized thiols and EZ-Link Maleimide- $\mathrm{PEG}_{2}$-Biotin (Mal-PEG $\mathrm{P}_{2}$-Bio, Thermofisher) to label the newly reduced thiols (Fig. 1A). Briefly, 12mg of TCA/acetone precipitated proteins were used for alkylation with $3 \mathrm{mM}$ NEM in $0.5 \mathrm{M}$ Tris , $1 \%$ SDS (BioShop) $\mathrm{pH} 7.3$ for 30min at room temperature (RT). Next, reduction was performed using 4mM TCEP in $0.5 \mathrm{M}$ Tris , $1 \% \mathrm{SDS} \mathrm{pH}$ 7.0 for $1 \mathrm{~h}$ at RT followed by labeling with $0.25 \mathrm{mM}$ Mal- $\mathrm{PEG}_{2}-\mathrm{Bio}$ for $2 \mathrm{~h}$ at RT.

\section{In-solution trypsin digestion of Mal-PEG 2 -Bio-labeled proteins}

In the In-solution trypsinization with Peptide Extraction (InsPEx) method (Fig. 1B), Mal$\mathrm{PEG}_{2}$-Bio-labeled proteins were precipitated with acetone. Pellets were resuspended in $0.5 \mathrm{M}$ Tris containing $1 \%$ SDS pH 7.0 before quantification using the BCA (Pierce Thermoscientific) method. Ten $\mathrm{mg}$ of proteins were acetone precipitated and pellets were resuspended in $50 \mathrm{mM}$ Tris $-\mathrm{HCl} \mathrm{pH}$ 7.0, 8M Urea (Sigma Aldrich), 20mM 1,4-Dithiothreitol (DTT, Sigma Aldrich) before incubation at $60^{\circ} \mathrm{C}$ for $1 \mathrm{~h}$. Next, samples were diluted with $50 \mathrm{mM}$ Tris-HCl pH 7.0 to decrease urea concentration to $1 \mathrm{M}$. Trypsin was added to a final protease:protein ratio of $1: 30(\mathrm{w} / \mathrm{w})$ and digestion was performed $\mathrm{ON}$ at $37^{\circ} \mathrm{C}$. To maximize the digestion, additional Trypsin was added after $4 \mathrm{~h}$ of incubation to a final protease:protein ratio of $1: 30(\mathrm{w} / \mathrm{w})$.

\section{Liquid-solid phase extraction of trypsin-digested peptides}

Trypsin activity was stopped by addition of $0.1 \%$ trifluoroacetic acid (TFA, SigmaAldrich), $\mathrm{pH} 1.0$ to the digestion mix described above before centrifugation at $20000 \mathrm{~g}$ for $20 \mathrm{~min}$ at RT. The supernatant containing the digested peptides was transferred to a new tube and the pellet was further extracted with a solution of $0.1 \%$ TFA to make sure all digested peptides were collected. Supernatants of both extractions were pooled and used for the next step (Fig. 1B). 
Peptides were desalted and extracted, according to the protocol described in (97), with modifications detailed in (98). In brief, Sep-Pak tC18 solid-phase extraction cartridges (Waters) were sequentially equilibrated with 1) $100 \%$ acetonitrile (Sigma Aldrich), 2) $0.5 \%$ acetic acid (Sigma Aldrich) and 50\% acetonitrile, and 3) 0.1\% TFA. Supernatants containing the digested peptides were loaded on the cartridges and sequentially washed with $0.1 \%$ TFA and with $0.5 \%$ acetic acid. Peptides were eluted into a clean tube with $1 \mathrm{~mL}$ of $0.5 \%$ acetic acid and $80 \%$ acetonitrile and distributed into multiple tubes containing $150 \mu \mathrm{L}$ before complete evaporation using a speed vacuum concentrator (Savant SVC 100H).

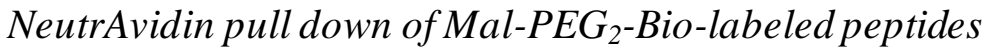

The dried peptide pellets described above were resuspended in HENS buffer composed of 250mMHEPES (BioShop) pH 7.7, 1mMEDTA (BioShop), 0.1 mMNeocuproine (Sigma Aldrich) and $1 \%$ SDS before addition of 2 volumes of neutralization buffer containing $20 \mathrm{mM} \mathrm{HEPES} \mathrm{pH}$ 7.7, $100 \mathrm{mM} \mathrm{NaCl}$ (BioShop), 1mM EDTA and 0.5\% (v/v) Triton X-100 (BioShop). Incubation with $200 \mu \mathrm{L}(50 \%$ slurry) NeutrAvidin agarose resin (ThermoFisher, Pierce) was performed overnight $(\mathrm{O} / \mathrm{N})$ at $4{ }^{\circ} \mathrm{C}$. After 5 washes with a solution of $20 \mathrm{mM}$ HEPES pH $7.7,600 \mathrm{mM} \mathrm{NaCl}$, $1 \mathrm{mM}$ EDTA and $0.5 \%$ Triton X-100, 2 washes with ddPBS and a final wash with UltraPure Distilled Water (Invitrogen), peptides were eluted with $8 \mathrm{M} \mathrm{Guanidine/HCl}$ (Sigma Aldrich) $\mathrm{pH}$ 1.5 .

\section{LC-MS/MS mass spectrometry}

Before LC-MS/MS analysis, the $\mathrm{pH}$ of eluted peptides was corrected to 7.4 by addition of $1 \mathrm{M}$ Tris/HCl, $\mathrm{pH}$ 7.4. LC-MS/MS analysis was performed on an Orbitrap Fusion Lumos Tribrid mass spectrometer (Thermo Scientific) operated with Xcalibur (version 4.0.21.10) and coupled to a Thermo Scientific Easy-nLC (nanoflow Liquid Chromatography) 1200 system at the Southem Alberta Mass Spectrometry (SAMS) facility of the University of Calgary (Alberta, Canada). Tryptic peptides were loaded onto a C18 trap (2 cm x $75 \mathrm{um}$; ThermoScientific PN164946) at a flow rate of $2 \mathrm{ul} / \mathrm{min}$. Peptides were then eluted and separated using an Easy Spray Column $(50 \mathrm{~cm}$ x 75 um; ThermoScientific PN ES803) and a 45 min gradient from 5 to $40 \%$ (5\% to $28 \%$ in 40 min followed by an increase to $40 \% \mathrm{~B}$ in $5 \mathrm{~min})$ of solvent B ( $0.1 \%$ formic acid in $80 \%$ LC-MS grade acetonitrile) at a flow rate of $0.3 \mu \mathrm{L} / \mathrm{min}$. Solvent $\mathrm{A}$ was composed of $0.1 \%$ formic acid and $3 \%$ acetonitrile in LC-MS grade water. Peptides were then electrosprayed using $2.3 \mathrm{kV}$ voltage into the ion transfer tube $\left(300^{\circ} \mathrm{C}\right)$ of the Orbitrap Lumos operating in positive mode. The Orbitrap first performed a full MS scan at a resolution of 120000 FWHM to detect the precursor ion having a m/z between 375 and 1575 and a +2 to +7 charge. The Orbitrap AGC (Auto Gain control) and the maximum injection time were set at $4 \mathrm{e} 5$ and $50 \mathrm{~ms}$, respectively. The Orbitrap was operated using the top speed mode with a 3 sec cycle time for precursor selection. The most intense precursor ions presenting a peptidic isotopic profile and having an intensity threshold of at least 5000 were isolated using the quadruple and fragmented with HCD (30\% collision energy) in the ion routing multipole. The fragment ions (MS2) were analyzed in the ion trap at a rapid scan rate. Dynamic exclusion was enabled for $30 \mathrm{sec}$ to avoid the acquisition of same precursor ion having a similar $\mathrm{m} / \mathrm{z}$ (plus or minus $10 \mathrm{ppm}$ ). 


\section{LC-MS/MS data analysis}

The Lumos data files were converted into Mascot Generic Format (MGF) using RawConverter (v1.1.0.18; The Scripps Research Institute) operating in a data dependent mode. Monoisotopic precursors having a charge state of +2 to +7 were selected for conversion. This mgf file was used to search a database (Homo sapiens, NCBI; 99742 entries) using Mascot algorithm (Matrix Sciences; version 2.4), assuming the digestion enzyme trypsin at a maximum of 1 missed cleavage. Mascot was searched with a fragment ion mass tolerance of $0.60 \mathrm{Da}$ and a parent ion tolerance of 10.0 PPM. Oxidation of methionine (Met+15.99Da), alkylation of Cys with NEM (Cys+125.05Da) and modification of Cys with Mal-PEG 2 -Bio (Cys+525.23Da, Fig. 1C) were specified in the Mascot search parameters as variable modifications. The Mascot data files were imported into Scaffold (v4.8.4, Proteome Software Inc., Portland, OR) for comparison of different samples based on their mass spectral counting. Scaffold was used to validate MS/MS based peptide and protein identifications. For label-free quantification (LFQ), only peptides containing at least 1 Cys ox-PTMs and detected in at least two out of the three biological replicates were considered for spectral counting. Scaffold algorithms were used to perform standard cutoffs of significance for peptide ion signal peak intensity-based quantification $(52,99)$. Peptide identifications were accepted if they could be established at greater than $95.0 \%$ probability by the Peptide Prophet algorithm (100) with Scaffold delta-mass correction and a false discovery rate (FDR) $<1 \%$. Protein identification was accepted if it could be established at greater than $95.0 \%$ probability and contained at least 1 identified oxidized peptide. Protein probabilities were assigned by the Protein Prophet algorithm (101). Proteins that contained similar peptides and could not be differentiated based on MS/MS analysis alone were grouped to satisfy the principles of parsimony.

\section{Gene Ontology and KEGG pathways analysis}

Identified proteins containing Mal-PEG 2 -Bio-labelled Cys were subjected to Gene Ontology (GO) enrichment analysis using the Cytoscape software (version 3.6.0) with the BiNGO plugin $(53,54)$, which compare the number of labeled proteins against the total proteins known to belong to each GO term. To assess the enrichment of a GO term, the hypergeometric test was used. The Benjamini and Hochberg procedure was applied to control the FDR and correct the $\mathrm{p}$ values (102). Adjusted p-value $<0.05$ were considered significant. Networks with overrepresented GO categories after correction were mapped. For pathway analyses, the ClueGO plugin was used (55) with the analysis mode "functions" to list the pathways enriched in Mal-PEG 2 -Bio-labelled Cys within the Kyoto Encyclopedia of Genes and Genomes(KEGG) database. Statistical analyses were done using a hypergeometric test, with the Benjamini and Hochberg procedure for p-value correction. ClueGO layout was used to visualize enriched pathways.

Preparation of Whole Cell Extracts (WCE)

Samples were kept on ice during all steps. Cells were harvested in cold ddPBS, transferred into $1.5 \mathrm{~mL}$ tubes and centrifuged at $16200 \mathrm{~g}, 4^{\circ} \mathrm{C}$ for $20 \mathrm{sec}$. Pellets were resuspended in $70 \mu \mathrm{L}$ RIPA lysis buffer constituted of 50mM Tris pH 7.5, 150mM NaCl, 2mM EDTA, $0.1 \%$ SDS, $1 \%$ Triton and $1 \%$ Sodium Deoxycolate completed with $10 \mu \mathrm{g} / \mathrm{mL}$ leupeptin, $10 \mu \mathrm{g} / \mathrm{mL}$ aprotinin, $10 \mu \mathrm{g} / \mathrm{mL}$ pepstatin, $30 \mathrm{mM} \mathrm{NaF}, 1 \mathrm{mM}$ activated Na3 VO4, $1 \mathrm{mM}$ p-nitrophenyl phosphate and $10 \mathrm{mM} \beta$-glycerophosphate. For reducing vs non-reducing SDS-PAGE experiments, RIPA buffer was also supplemented with 100mM NEM. After 20min incubation for in lysis buffer, samples were sonicated at $40 \%$ with 3 X 15 pulses of $0.8 \mathrm{sec}$ with round s on ice in between. Samples were 
centrifuged at $800 \mathrm{~g}$ at $4^{\circ} \mathrm{C}$ for $10 \mathrm{~min}$. The supernatants were kept and quantified using the DC method (DC Protein Assay Kit, Bio-Rad).

\section{Semi-Denaturing Detergent Agarose Gel Electrophoresis (SDD-AGE)}

Fresh WCE were resolved by SDD-AGE following the protocol detailed in (103 9356) with the modifications reported in (104). Briefly, thirty $\mu \mathrm{g}$ of WCE completed with one-third volume of $4 \mathrm{X}$ loading dye (20\% glycerol, $8 \%$ SDS and bromophenol blue in 2x TAE buffer) were incubated for $5 \mathrm{~min}$ at RT before resolution in a vertical $1.5 \%$ agarose gel. The running buffer consisted of TAE $1 \mathrm{X}$ supplemented with $0.1 \%$ SDS. To transfer the proteins to a nitrocellulose membrane, a liquid transfer was performed overnight at $4^{\circ} \mathrm{C}$ at $20 \mathrm{~V}$ constant using transfer buffer containing $25 \mathrm{mM}$ Tris-Base, $192 \mathrm{mM}$ glycine, $0.1 \%$ SDS and $10 \% \mathrm{EtOH}$. To better exposed the epitopes, membranes were treated with $0.5 \%$ glutaraldehyde (LifeSensors) in dPBS for 20 min before immunoblots (1059872).

\section{Non-reducing/reducing SDS-PAGE}

SDS-PAGE electrophoresis was performed as detailed in (106) using $12 \%$ acrylamide/bisacrylamide (37.5:1, Bioshop) resolution gel and a stacking gel of 3\% acrylamide/bis-acrylamide

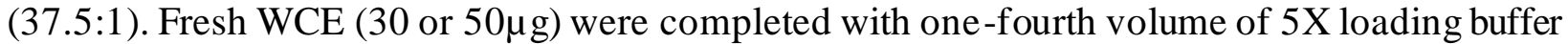
(125 mM Tris-HCl pH 6.8 (RT), 10\% SDS, 20\% glycerol, $0.0005 \%$ bromophenol blue). For the reducing conditions, $250 \mathrm{mM}$ DTT was added to the loading buffer. Samples were incubated for $5 \mathrm{~min}$ at $100^{\circ} \mathrm{C}$. Heating was quenched by a $2 \mathrm{~min}$ incubation on ice. Both the stacking and resolution gels were transferred onto nitrocellulose using a buffer supplemented with $0.036 \%$ SDS and $10 \%$ Ethanol.

\section{Immunoblot analysis}

Following protein transfer, nitrocellulose membranes were probed with protein-specific primary antibodies diluted in PBS containing 5\% Milk or 5\% BSA as follows: anti-actin Cat \#A5441 from Sigma Aldrich; anti-tubulin Cat \#5286 from Santa Cruz; anti-Flag M2 Cat \#SLBF6631V from Sigma Aldrich; anti-Phospho-STING (Ser $\left.{ }^{366}\right)$ Cat\#19781 from Cell signaling, anti-STING Cat \#13647 from Cell signaling; anti-Phospho-TBK1 (Ser ${ }^{172}$ ) Cat \#5483 from Cell signaling; anti-TBK1/IKK\& Cat \#IMG270A from Imgenex. Membranes were washed using dPBS containing $0.5 \%$ Tween (PBS-T) before incubation with horseradish peroxidase (HRP)-conjugated secondary antibodies (Seracare or Jackson Immunoresearch Laboratories). After final wa shes, enhanced chemiluminescence using the Western Lightning Chemiluminescence Reagent Plus (Perkin-Elmer Life Sciences) was performed to identify immunoreactive bands detected using a LAS4000mini CCD camera apparatus (GE healthcare).

\section{Immunofluorescence microscopy}

Transfected HEK293T were seeded in Poly-L-Lysine coated 96-well clear bottom plates (Corning Incorporated; plate number 3882 half-area microplates) before fixation with 3.7\% formaldehyde for $15 \mathrm{~min}$ at $37^{\circ} \mathrm{C}$ and permeabilization with $0.5 \%$ Triton $\mathrm{X}-100$ in ddPBS containing $0.5 \mathrm{mM} \mathrm{CaCl} 2,1 \mathrm{mM} \mathrm{MgCl} 2$ (PBS/Ca/Mg) for $20 \mathrm{~min}$ at RT. After blocking with $2 \%$ BSA, $0.2 \%$ Tween-20 in $\mathrm{PBS} / \mathrm{Ca} / \mathrm{Mg}$ for $20 \mathrm{~min}$ at $\mathrm{RT}$, protein were immunodetected by incubation overnight at $4^{\circ} \mathrm{C}$ with the Anti-DYKDDDDK Tag (D6W5B) Rabbit mAb (Cell Sign \#14793; recognizes the Flag epitope) followed by Donkey anti-Rabbit, Alexa Fluor 647 (Invitrogen A-31573) secondary antibody for 90min at RT. Nuclei were counterstained with 4',6'Diamidino-2-phenylindole (DAPI; \#D9564; Sigma) diluted 1/1500 in PBS/Ca/Mg for 5min. Plates 
were stored in the dark at $4{ }^{\circ} \mathrm{C}$ prior to imaging using a $40 \mathrm{x}$ objective mounted on an Operetta High-Content Imaging System (Perkin Elmer) controlled by Harmony 4.1 software.

\section{Structure analysis.}

The available STING structures in the protein data bank (PDB) database (107) were downloaded and visualized using PyMOL (Schrödinger, Inc. version 2.2.3). The PyTMplugin was used to sulfenyl (S-OH) on Cys ${ }^{206}$. Sulfenylation was used given that it is the first ox-PTMs happening before subsequent glutathionylation or disulfide bond formation $(7,108)$. The APBS Electrostatics plugin was used to visualize the electrostatic surfaces $(109,110)$. The CEalign plugin was used to perform superposition of the structures and the computation of the difference of the root-mean-square deviation of atomic positions (RMSD) (111).

\section{IFN $\beta$ promoter luciferase gene reporter assay}

HEK293 T cells were cotransfected with the IFN $\beta$-pGL3 firefly (112), the pRL-null renilla (Promega, internal control) luciferase reporter plasmids together with the STING encoding plasmid. At $24 \mathrm{~h}$, cells were stimulated or not with $100 \mu \mathrm{M} \mathrm{HOCl}$ for $24 \mathrm{~h}$. Where indicated cells were transfected with or without 2'3'-cGAMP at 8 or $24 \mu \mathrm{g} / \mathrm{mL} 1 \mathrm{~h}$ before treatment with HOCl. The cells were collected and assayed for reporter gene activities using the Dual-luciferase reporter assay system (Promega). The firefly/renilla luciferase ratios were calculated to determine luciferase activities. Statistical analyses were performed using the Prism 8 software (GraphPad) using the indicated tests. Statistical significance was assessed using the following $\mathrm{p}$ values: $\mathrm{p}<$ $0.05(*), \mathrm{p}<0.01(* *), \mathrm{p}<0.001(* * *)$ or $\mathrm{p}<0.0001(* * * *)$. p values $<0.05$ were considered significant.

\section{Supplementary Materials}

Fig. S1. Workflow of the bioswitch labeling strategy coupled to in gel trypsin digestion for identification of Cys ox-PTMs by MS in vivo.

Fig. S2. Validation of the InsPEx bioswitch method.

Fig. S3. Community analysis of the GO terms enriched in Cys ox-PTMs.

Fig. S4. Complete map of all enriched KEGG pathways.

Fig. S5. MS identification of STING Cys oxidation sites after 2'3'-cGAMP stimulation.

Fig. S6. STING forms intramolecular disulfide bonds independently of Cys ${ }^{148}$ and Cys ${ }^{206}$.

Fig. S7. STING aggregates formed in response to 2'3'-cGAMP are sensitive to reducing agents.

Fig. S8. Model of STING regulation by Cys ox-PTMs.

Data file S1. Mal-PEG 2 -Bio-modified peptides found in the pilot in-gel trypsinization approach in THP1 cells upon diamide treatment.

Data file S2. Mal-PEG 2 -Bio-modified peptides found using the InsPEx approach in U937 cells upon diamide treatment.

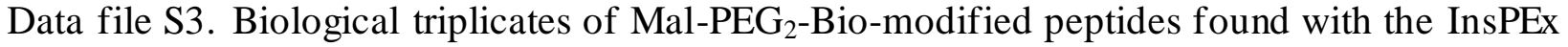
bioswitch approach at basal levels and upon diamide and $\mathrm{HOCl}$ stimulations. 
Data file S4. List of all Gene Ontology (GO) terms that are enriched in Cys ox-PTM at basallevels and upon diamide/HOCl stimulations. Biological processes, molecular functions and cell component are listed in different sheets.

Data file S5. List of all KEGG pathways found enriched in oxidized proteins at basal levels and upon diamide/ $\mathrm{HOCl}$ stimulations.

\section{References:}

1. N. Grandvaux, M. Mariani, K. Fink, Lung epithelial NOX/DUOX and respiratory virus infections. Clinical science (London, England: 1979) 128,337-347 (2015).

2. O. A. Khomich, S. N. Kochetkov, B. Bartosch, A. V. Ivanov, Redox Biology of Respira tory Viral Infections. Viruses 10, (2018).

3. A. N. Colado Simao, V. J. Victorino, H. K. Morimoto, E. M. Reiche, C. Panis, Redox-driven events in the human immunodeficiency virus type 1 (HIV-1) infection and their clinical implications. Current HIV research 13,143-150(2015).

4. J. Hu et al., The role of oxidative stress in EBV ly tic reactivation, ra dioresistance and the potential preventive and therapeutic implications. Int J Cancer 141,1722-1729 (2017).

5. Z. Li et al., Roles of reactive oxygen species in cell signaling pathways and immune responses to viral infections. Arch Virol 162, 603-610 (2017).

6. J. Choi, N. L. Corder, B. Koduru, Y. Wang, Oxidative stress and hepatic Nox proteins in chronic hepatitis C and hepatocellularcarcinoma. Free Radic BiolMed 72, 267-284(2014).

7. C. E. Paulsen, K. S. Ca rroll, Cysteine-mediated redox signaling: chemistry, biology, and tools for discovery. Chem Rev 113, 4633-4679(2013).

8. S. G. Rhee, I. S. Kil, Multiple Functions and Regulation of Mammalian Peroxiredoxins. Annual review of biochemistry 86, 749-775(2017).

9. R. Radi, Oxygen radicals, nitric oxide, and peroxynitrite: Redox pathways in molecular medicine. Proceeding s of the National Academy of Sciences 115, 5839-5848 (2018).

10. K. Araki et al., Redox Sensitivities of Global Cellular Cysteine Residues under Reductive and Oxidative Stress. J Proteome Res 15, 2548-2559 (2016).

11. A. E. Armstrong, R. Zerbes, P. A. Fournier, P. G. Arthur, A fluorescent dual labeling technique for the quantitative measurement of reduced and oxidized protein thiols in tissue samples. Free Radic Biol Med $\mathbf{5 0}$, 510-517 (2011).

12. L. I. Leichert et al., Quantifying changes in the thiol redox proteome upon oxidative stress <em>in vivo</em>. Proceedings of the National Academy of Sciences 105, 8197-8202 (2008).

13. S. García-Santamarina et al., Monitoring in vivo reversible cysteine oxidation in proteins using ICAT and mass spectrometry. Nature protocols $\mathbf{9}, 1131$ (2014).

14. J. van der Reest, S. Lilla, L. Zheng, S. Zanivan, E. Gottlieb, Proteome-wide analy sis of cysteine oxidation reveals metabolic sensitivity to redox stress. Nature communications $\mathbf{9 , 1 5 8 1}$ (2018).

15. O. Rudyk, P. Eaton, Biochemical methods for monitoring protein thiol redox states in biological systems. Redox biology 2, 803-813 (2014).

16. A. Miseta, P. Csutora, Relationship between the occurrence of cysteine in proteins and the complexity of orga nisms. Molecular biologyandevolution 17,1232-1239 (2000).

17. A. E. Boyatzis et al., Limiting the Hydrolysis and Oxidation of Maleimide-Peptide Adducts Improves Detection of Protein Thiol Ox idation. Journal of Proteome Research 16, 2004-2015 (2017).

18. P. Marinelli et al., A single cysteine post-translational oxidation suffices to compromise globular proteins kinetic sta bility and promote amyloid formation. Redoxbiology 14, 566-575 (2018).

19. K.-S. Yang et al., Inactivation of Human Peroxiredoxin I during Catalysis as the Result of the Oxidation of the Catalytic Site Cysteine to Cysteine-sulfinic Acid. Journal of Biological Chemistry 277, 38029-38036 (2002).

20. F. Klamt et al., Oxidant-induced apoptosis is mediated by oxidation of the actin-regulatory protein cofilin. Nature cell biology 11, 1387 (2009). 
21. D. E. Heppner et al., Direct cysteine sulfenylation drives activation of the Src kinase. Nature communications 9, $4522(2018)$.

22. H. Østergaard, C. Tachibana, J. R. Winther, Monitoring disulfide bond formation in the eukaryotic cytosol. The Journal of cell biology 166,337-345(2004).

23. H. Ishikawa, G. N. Barber, STING is an endoplasmic reticulum adaptor that facilitates innate immune signa lling. Nature 455, 674 (2008).

24. W. Sun et al., ERIS, an endoplasmic reticulum IFN stimulator, activates innate immune signaling through dimerization. Proc Natl Acad Sci US A 106, 8653-8658 (2009).

25. B. Zhong et al., The adaptor protein MITA links virus-sensing receptors to IRF3 transcription factor activation. Immunity 29, 538-550 (2008).

26. L. Jin et al., STING/MPYS mediates host defense against Listeria monocytogenes infection by regulating Ly6C(hi) monocyte migration. J Immunol 190, 2835-2843 (2013).

27. K. Kato,H. Omura, R. Ishitani, O. Nureki, Cyclic GMP-AMP as an Endogenous Second Messenger in Innate Immune Signaling by Cytosolic DNA. Annual review ofbiochemistry 86, 541-566 (2017).

28. L. Sun, J. Wu, F. Du, X. Chen, Z. J. Chen, Cyclic GMP-AMP synthase is a cytosolic DNA sensor that activates the type I interferon pathway. Science 339, 786-791 (2013).

29. X. Zhang et al., Cyclic GMP-AMP containing mixed phosphodiester linkages is an endogenous high-affinity ligand for STING. Mol Cell51, 226-235(2013).

30. A. Abla sser et al., cGAS produces a 2'-5'-linked cyclic dinucleotide second messenger that activates STING. Nature 498, 380-384 (2013).

31. E. J. Diner et al., The innate immune DNA sensor cGAS produces a noncanonical cyclic dinucleotide that activates human STING. Cell Rep 3, 1355-1361 (2013).

32. P. Gao et al., Cyclic $\left[\mathrm{G}\left(2^{\prime}, 5^{\prime}\right) \mathrm{pA}\left(3^{\prime}, 5^{\prime}\right) \mathrm{p}\right]$ is the metazoan second messenger produced by DNA-activated cyclic GMP-AMP synthase. Cell 153, 1094-1107 (2013).

33. X. Tan, L. Sun, J. Chen, Z. J. Chen, Detection of Microbial Infections Through Innate Immune Sensing of Nucleic Acids. Annual review of microbiology 72, 447-478(2018).

34. S. R. Woo et al., STING-dependent cytosolic DNA sensing mediates innate immune recognition of immunogenic tumors. Immunity 41, 830-842 (2014).

35. L. Corrales et al., Direct Activation of STING in the Tumor Microenvironment Leads to Potent and Systemic Tumor Regression and Immunity. Cell Rep 11, 1018-1030(2015).

36. L. Deng et al., STING-Dependent Cytosolic DNA Sensing Promotes Radiation-Induced Type I InterferonDependent Antitumor Immunity in Immunogenic Tumors. Immunity 41, 843-852 (2014).

37. M. Motwani, S. Pesiridis, K. A. Fitzgerald, DNA sensing by the cGAS-STING pathway in health and disease. Nature reviews. Genetics 20, 657-674 (2019).

38. J. Bai, F. Liu, The cGAS-cGAMP-STING Pathway: A Molecular Link Between Immunity and Metabolism. Diabetes 68, 1099-1108 (2019).

39. N. Dobbs et al., STING Activation by Translocation from the ER Is Associated with Infection and Autoinflammatory Disease. Cell Host Microbe 18, 157-168(2015).

40. K. Mukai et al., Activation of STING requires palmitoylation at the Golgi. Nature communications 7, 11932 (2016).

41. S. Sharma et al., Triggering the interferon antiviral response through an IKK-related pathway. Science 300, 1148-1151. (2003).

42. K. A. Fitzgerald et al., IKKepsilon and TBK1 are essential components of the IRF3 signaling pa thway. Nat Immunol 4, 491-496. (2003).

43. Y. Tanaka, Z. J. Chen, STING specifies IRF3 phosphorylation by TBK1 in the cytosolic DNA signaling pathway. Sci Signal 5, ra20(2012).

44. Y.-M. Go, J. D. Chandler, D. P. Jones, The cysteine proteome. Free radical biology \& medicine 84, 227-245 (2015).

45. P. L. Tan, T. Sha vlakadze, M.D. Grounds, P. G. Arthur, Differential thiol oxidation of the signaling proteins Akt, PTEN or PP2A determines whether Akt phosphoryla tion is enhanced or inhibited by oxidative stress in C2C12 myotubes derived from skeletal muscle. Int J Biochem Cell Biol 62, $72-79$ (2015).

46. N. S. Kosower, E. M. Kosower, in Methods in enzymology. (Academic Press, 1995), vol. 251, pp. 123-133.

47. C. Barry, T. Key, R. Haddad, R. Duncan, Features of a spatially constrained cystine loop in the p10 FAST protein ectodomain define a new class of viral fusion peptides. The Joumal of biological chemistry $\mathbf{2 8 5}$, 16424-16433 (2010). 
48. A. G. Cox, A. V. Peskin, L. N. Paton, C. C. Winterbourn, M. B. Hampton, Redox potential and peroxide reactivity of human peroxired oxin 3. Biochemistry 48, 6495-6501 (2009).

49. N. T. Moldogazieva, I. M. Mokhosoev, N. B. Feldman, S. V. Lutsenko, ROS and RNS signalling: adaptive redox switches through oxidative/nitrosative protein modifications. Free radical research 52, 507-543 (2018).

50. B. Cha mi, N. J. J. Martin, J. M. Dennis, P. K. Witting, Myeloperoxidase in the inflamed colon: Anovel ta rget for treating inflammatory bowel disea se. Archives of biochemistry and biophysics 645, 61-71 (2018).

51. N. S. Gould et al., Site-Specific Proteomic Mapping Identifies Selectively Modified Regulatory Cysteine Residues in Functionally Distinct Protein Networks. Chem Biol 22, 965-975 (2015).

52. L. Song, F. Wang, Z. Dong, X. Hua, Q. Xia, Label-free quantitative phosphoproteomic profiling of cellular response induced by an insectcy tokine paralytic peptide. Journal of proteomics 154, 49-58 (2017).

53. P. Shannon et al., Cytoscape: a software environment for integrated models of biomolecular interaction networks. Genome research 13, 2498-2504 (2003).

54. S. Ma ere, K. Heymans, M. Kuiper, BiNGO: a Cytoscape plugin to assess overrepresentation of gene ontology categories in biological networks. Bioinformatics 21,3448-3449(2005).

55. G. Bindea et al., ClueGO: a Cytoscape plug-in to decipher functionally grouped gene ontology and pathway annotation networks. Bioinformatics 25, 1091-1093 (2009).

56. S. Liu et al., Phosphorylation of innate immune a daptor proteins MAVS, STING, and TRIF induces IRF3 activation. Science 347, aaa2630 (2015).

57. X. Ma et al., Molecular basis of Tank-binding kinase 1 activation by transautophosphorylation. Proc Natl Acad Sci US A 109, 9378-9383 (2012).

58. L. Jin et al., MPYS is required for IFN response factor 3 activation and typeI IFN production in the response of cultured phagocytes to bacterial second messengers cyclic-di-AMP and cyclic-di-GMP. J Immunol 187, 2595-2601 (2011).

59. T. Saitoh et al., Atg9a controls dsDNA-driven dynamic translocation of STING and the innate immune response. ProcNatl Acad SciUS A 106, 20842-20846(2009).

60. L. Jin, L. L. Lenz, J. C. Cambier, Cellular rea ctive oxygen species inhibit MPYS induction of IFNbeta. PLoS One 5, e15142(2010).

61. S. L. Ergun, D. Fernandez, T. M. Weiss, L. Li, STING Polymer Structure Reveals Mechanisms for Activation, Hyperactivation, and Inhibition. Cell 178, 290-301.e210 (2019).

62. P. Gao et al., Structure-function analysis of STING activation by c $\left[\mathrm{G}\left(2^{\prime}, 5^{\prime}\right) \mathrm{pA}\left(3^{\prime}, 5^{\prime}\right) \mathrm{p}\right]$ and targeting by antiviral DMXAA. Cell 154, 748-762 (2013).

63. H. Shi, J. Wu, Z. J. Chen, C. Chen, Molecular basis for the specific recognition of the metazoan cyclic GMPAMP by the innate immune adaptor protein STING. Proceedings of the National Academy of Sciences 112, 8947-8952(2015).

64. S. Ouyang et al., Structural a naly sis of the STING a daptor protein reveals a hydrophobic dimer interface and mode of cyclic di-GMP binding. Immunity 36, 1073-1086 (2012).

65. Q. Yin et al., Cyclic di-GMP sensing via the innateimmune signaling protein STING. Mol Cell 46, 735-745 (2012).

66. A. Warnecke, T. Sandalova, A. Achour, R. A. Harris, PyTMs: a useful PyMOL plugin for modeling common post-translational modifications. BMC Bioinformatics 15,370 (2014).

67. S. Riquier et al., Peroxiredoxin post-tran slational modifications by redox messengers. Redoxbiology 2 , 777785 (2014).

68. G. Sager, S. Gabaglio, E. Sztul, G. A. Belov, Role of Host Cell Secretory Machinery in Zika Virus Life Cycle. Viruses 10, (2018).

69. D. Dou, R. Revol, H. Ostbye, H. Wang, R. Daniels, Influenza A Virus Cell Entry, Replication, Virion Assembly and Movement. Frontiers in immunology 9, 1581 (2018).

70. C. Mathew, R. Ghildyal, CRM1 Inhibitors for Antiviral Therapy. Frontiers in microbiology 8,1171 (2017).

71. V. Le Sa ge, A. J. Mouland, Viral subversion of the nuclear pore complex. Viruses 5, 2019-2042(2013).

72. N. Crampton et al., Oxidative Stress Inhibits Nuclear Protein Export by Multiple Mechanisms That Target FG Nucleoporins and Crm1. Molecular Biology of the Cell 20,5106-5116(2009).

73. S. H. Yoshimura, S. Otsuka, M. Kumeta, M. Taga, K. Takeyasu, Intermolecular disulfide bonds among nucleoporins regulate karyopherin-dependent nuclear transport. Journal of Cell Science, jcs.124172 (2013).

74. H.C. Huang, T. Nguyen, C.B. Pickett, Regulation of the antioxidant response element by protein kinaseCmediated phosphorylation of NF-E2-related factor 2. Proc Natl Acad Sci U S A 97, 12475-12480 (2000). 
75. D. Olagnier et al., Nrf2 negatively regulates STING indicating a link between antiviral sensing and metabolic reprogramming. Nature communications $\mathbf{9 , 3 5 0 6}$ (2018).

76. C. Gunderstofte et al., Nrf2 Negatively Regulates Type I Interferon Responses and Increases Susceptibility to Herpes Genital Infection in Mice. Frontiers in immunology 10, 2101 (2019).

77. L. Tao etal. (bioRxiv, 2019).

78. Z. Li et al., PPM1 A regulates antiviral signaling by antagonizing TBK1-mediated STING phosphory lation and aggregation. PLoS Pathog 11, e1004783 (2015).

79. K. Motani, S. Ito, S. Na gata, DNA-Media ted Cyclic GMP-AMP Synthase-Dependent and -Independent Regulation of Innate Immune Responses. J Immunol 194, 4914-4923 (2015).

80. K. L. Jonsson et al., IFI16 is required for DNA sensing in human macrophages by promoting production and function of GAMP. Nature communications 8, 14391 (2017).

81. Y. H. Huang, X. Y. Liu, X. X. Du, Z. F. Jiang, X. D. Su, The structural basis for the sensing and binding of cyclic di-GMP by STING. Nature structural \& molecular biology 19, 728-730 (2012).

82. J. M. Ramanjulu et al., Author Correction: Design of amidobenzimidazole STING receptor agonists with systemic activity. Nature 570, E53 (2019).

83. C. Shu, G. Yi, T. Watts, C.C.Ka o, P.Li, Structure of STING bound to cyclic di-GMP reveals the mechanism of cyclic dinucleotide recognition by the immune system. Nature structural \& molecular biology 19, $722-$ 724 (2012).

84. G. Shang et al., Crystal structures of STING protein reveal basis for recognition of cyclic di-GMP. Nature structural \& molecular biology 19, 725-727 (2012).

85. B. Zha o et al., A conserved PLPLRT/SD motif of STING mediates the recruitment and activ ation of TBK1. Nature 569, 718-722 (2019).

86. B. Zha o et al., Structural basis for concerted recruitment and activation of IRF-3 by innate im mune adaptor proteins. Proc Natl Acad Sci US A 113, E3403-3412(2016).

87. T. Siu et al., Discovery of a Novel cGAMP Competitive Ligand of the Inactive Form of STING. ACS medicinal chemistry letters 10,92-97 (2019).

88. G. Shang, C.Zhang, Z. J. Chen, X. C. Bai, X. Zhang, Cryo-EM structures of STING reveal its mechanism of activation by cyclic GMP-AMP. Nature 567, 389-393 (2019).

89. B. Novotna et al., Enzymatic Preparation of 2'-5',3'-5'-Cyclic Dinucleotides, Their Binding Properties to Stimula tor of Interferon Genes Adaptor Protein, and Structure/Activity Correlations. Journal of medicinal chemistry 62, 10676-10690(2019).

90. P. Gao et al., Binding-pocket and lid-region substitutions render human STING sensitive to the speciesspecific drug DMXAA. Cell Rep 8, 1668-1676 (2014).

91. M. Smola, G. Birkus, E. Boura, No magnesium is needed for binding of the stimulator of interferon genes to cyclic dinucleotides. Acta crystallographica. Section F, Structural biology communications 75, 593-598 (2019).

92. I. Melki et al., Disea se-a ssociated mutations identify a novel region in human STING necessary for the control of ty pe I interferon signaling. Journal of Allergy and Clinical Immunology 140, 543-552 .e545 (2017).

93. L. A. Defelipe, E. Lanzarotti, D. Gauto, M. A. Marti, A. G. Turjanski, Protein topology determines cy steine oxida tion fate: the case of sulfenyl amide formation among protein families. PLoS Comput Biol11, e1004051 (2015).

94. Z. A. Wood, E. Schröder, J. Robin Harris, L. B. Poole, Structure, mechanism and regulation of peroxiredoxins. Trends in Biochemical Sciences 28, 32-40 (2003).

95. C.Zhang et al., Structural basis of STING binding with and phosphorylation by TBK1. Nature 567, 394-398 (2019).

96. J. J. Woodward, A. T. Iavarone, D. A. Portnoy, c-di-AMP secreted by intracellular Listeria monocytogenes activates a host type I interferon response. Science 328, 1703-1705 (2010).

97. J. Villen, S. P. Gygi, The SCX/IMAC enrichment approach for global phosphorylation analysis by mass spectrometry. Nature protocols 3, 1630-1638(2008).

98. L. M. Schiapparelli et al., Direct detection of biotinylated proteins by mass spectrometry. J Proteome Res 13,3966-3978(2014).

99. M.H.D. R. Al Shweiki et al., Assessment of Label-Free Quantification in Discovery Proteomics and Impact of TechnologicalFactors and Natural Variability of Protein Abundance. Journal of Proteome Research 16, 1410-1424(2017).

100. A. Keller, A. I. Nesvizhskii, E. Kolker, R. Aebersold, Empiricalstatistical model to estimate the accuracy of peptide identifications made by MS/MS and database search. Analytical chemistry 74, 5383-5392 (2002). 
101. A. I. Nesvizhskii, A. Keller, E. Kolker, R. Aebersold, A statistical model for identifying proteins by tandem mass spectrometry. Analytical chemistry 75, 4646-4658(2003).

102. Y. Benjamini, D. Yekutieli, The control of the false discovery ra te in multiple testing under dependency. Ann. Statist. 29, 1165-1188(2001).

103. R. Halfmann, S. Lindquist, Screening for Am yloid Aggregation by Semi-Denaturing Detergent-Agarose Gel Electrophoresis. Journal of Visualized Experiments : JoVE, 838 (2008).

104. N. Zamorano Cuervo, Q. Osseman, N. Grandvaux, Virus Infection Triggers MAVS Polymers of Distinct Molecular Weight. Viruses 10, (2018).

105. V. Seiberlich, O. Goldbaum, V.Zhukareva, C. Richter-Landsberg, The smallmolecule inhibitor PR-619 of deubiquitinating enzymes affects the microtubule network a nd causes protein aggregate formation in neural cells: Implications for neurodegenerative diseases. Biochimica et Biophysica Acta (BBA) - Molecular Cell Research 1823,2057-2068(2012).

106. A. C. Robitaille, M. K. Mariani, A. Fortin, N. Grandvaux, A High Resolution Method to Monitor Phosphorylation-dependent Activation of IRF3. J Vis Exp, e53723 (2016).

107. H. M. Berman et al., The Protein Da ta Bank. Nucleic Acids Res 28, 235-242 (2000).

108. D. S. Rehder, C. R. Borges, Cysteine sulfenic acid as an intermediate in disulfide bond formation and nonenzymatic protein folding. Biochemistry 49, 7748-7755(2010).

109. E. Jurrus et al., Improvements to the APBS biomolecular solvation software suite. Protein Science : A Publication of the Protein Society 27, 112-128(2018).

110. N. A. Baker, D. Sept, S. Joseph, M. J. Holst, J. A. McCa mmon, Electrostatics of nanosystems: application to microtubules and the ribosome. Proc Natl Acad Sci US A 98, 10037-10041 (2001).

111. I. N. Shindyalov, P. E. Bourne, Protein structure alignment by incremental combinatorial extension (CE) of the optimal path. Protein engineering 11,739-747(1998).

112. A. Soucy-Faulkner et al., Requirement of NOX2 and reactive oxygen species for efficient RIG-I-mediated antiviral response through regulation of MAVS ex pression. PLoS Pathog 6, e1000930 (2010).

113. G. Su, A. Kuchinsky, J.H. Morris, D. J. States, F. Meng, GLay: community structure analysis of biological networks. Bioinformatics 26, 3135-3137 (2010).

114. I. Lassing et al., Molecular and structural basis for redox regulation of beta-actin. Journal of molecular biology 370, 331-348(2007).

115. M. Luo et al., Characterization of the Redox Activity and Disulfide Bond Formation in Apurinic/Apyrimidinic Endonuclease. Biochemistry 51,695-705 (2012).

116. J. Qu, G. H. Liu, B. Huang, C. Chen, Nitric oxide controls nuclear export of APE1/Ref-1 through Snitrosation of cy steines 93 and 310 . Nucleic Acids Res 35, 2522-2532 (2007).

117. M. Fernandez-Caggiano et al., Oxidant-induced Interprotein Disulfide Formation in Cardiac Protein DJ-1 Occurs via an Interaction with Peroxiredoxin 2. J Biol Chem 291, 10399-10410 (2016).

118. A. Weichsel, J. R. Gasda ska, G. Powis, W. R. Montfort, Crystal structures of reduced, oxidized, and mutated human thioredoxins: evidence for a regulatory homodimer. Structure 4, 735-751 (1996).

119. D. A. Mitchell, M. A. Marletta, Thioredoxin catalyzes the S-nitrosation of the caspase-3 active site cy steine. Nat Chem Biol 1, 154-158 (2005).

120. S. I. Hashemy, A. Holmgren, Regulation of the Catalytic Activity and Structure of Human Thioredoxin 1 via Oxidation and S-Nitrosylation of Cysteine Residues. Journal of Biological Chemistry 283, 21890-21898 (2008).

121. D. Peralta etal., A proton relay enhances $\mathrm{H} 2 \mathrm{O} 2$ sensitivity of GAPDH to facilitate metabolic a daptation. Nat Chem Biol 11, 156-163 (2015).

122. G. Birkenmeier et al., Posttranslational modification of human glyoxalase 1 indicates redox-dependent regulation. PLoS One 5, e10399 (2010).

123. M. Koutroumani, G. E. Papadopoulos, M. Vla ssi, E. Nikolakaki, T. Giannakouros, Evidence for disulfide bonds in SR Protein Kinase 1 (SRPK1) that are required for activity and nuclear localization. PLoS One 12, e0171328(2017).

124. D. J. Templeton, M. S. Aye, J. Rady, F. Xu, J. V. Cross, Purification of reversibly oxidized proteins(PROP) reveals a redox switch controlling p38 MAP kinase activity. PLoS One 5, e15012 (2010).

125. R. Bassi et al., Redox-dependent dimerization of p38alpha mitogen-activated protein kinase with mitogenactivated protein kinase kinase 3. J Biol Chem 292, 16161-16173 (2017).

126. H. Murata et al., Glutaredoxin exerts an antiapoptotic effect by regulating the redox state of Akt. J Biol Chem 278, 50226-50233 (2003). 
127. R. Wani et al., Isoform-specific regulation of Akt by PDGF-induced reactive oxygen species. Proceedings of the NationalAcademy of Sciences 108, 10550-10555 (2011).

Acknowledgments: We thank Dr. M. Servant (Université de Montréal, Quebec, Canada) for providing U937 cell line, Dr. K. Gee (Queens University, Ontario, Canada) for THP-1 cells and Dr. D. Lamarre (Université de Montréal, Quebec, Canada) for the STING encoding plasmid. We thank Dr. L. Brechenmacher at the Southern Alberta Mass Spectrometry (SAMS) facility of the University of Calgary (Alberta, Canada) for expert technical assistance. We also thank Dr. P. Arthur (University of Western-Australia, Australia) for help with the bioswitch labeling protocol and Dr. E. Lecuyer and X. Wang for help with immunofluorescence staining. Funding: The present work was funded by grants from the Canadian Institutes of Health Research (CIHR) [MOP-137099 and III-134054] and by the Research Chair in signaling in virus infection and oncogenesis from the Université de Montréal to NG. NZC was recipient of graduate studentships from the Faculty of Medicine, the Faculty of post-doctoral and graduate studies, Universite de Montréal, and the Fonds de recherche du Québec - Santé (FRQS). NZC, AF, EC and NG are members of the Réseau en Santé Respiratoire du Fonds de la Rechercheen Santé du Québec (RSRFRQS). Author contributions: NZC and NG designed the experiments. AF and SC optimized the bioswitch labeling technique. NZC and EC performed the experiments. NZC and NG analyzed the data and wrote the manuscript. Competing interests: The authors declare that they have no competing interests. Data and materials availability: Proteome wide mass spectrometry data will be available in the PRIDE database, accession number [ $\operatorname{xxxxxx}$.

\section{Figure Legends:}

Fig. 1. Identification of reversible Cys ox-PTMs induced by oxidants in vivo using unbiased Mal-PEG 2-Bio-based bioswitch labeling strategy coupled to mass spectrometry. AB. Schematic of the workflow used to label reversible Cys ox-PTMs with the Mal-PEG $2_{2}$ Bio bioswitch method (A) followed by In-solution trypsinization with peptide extraction (InsPEx, B) used to generate and isolate peptides containing at least one Mal-PEG $\mathrm{P}_{2} \mathrm{Bio}-$ labelled Cys for identification by LC-MS/MS. In (A), Cys-SH residues were specifically alkylated with N-ethylmaleimide (NEM). Reversibly oxidized Cys (SOx) were then reduced using tris(2-carboxyethyl)phosphine (TCEP) before labeling with EZ-Link Maleimide-PEG 2 -Biotin $\left(\mathrm{Mal}-\mathrm{PEG}_{2}-\mathrm{Bio}\right)$. In (B), proteins from (A) were digested in solution using trypsin and peptides were subjected to liquid -solid phase extraction followed by a NeutrAvidin pull down and analysis by LC-MS/MS. C. Schematic of a modified Cys residue carrying a Mal- $\mathrm{PEG}_{2}$-Bio moiety that adds a mass of 525.23 Da to the Cys. D. U937 cells were left untreated or stimulated with $0.5 \mathrm{mM}$ diamide or $100 \mu \mathrm{Mhypochlorous}$ acid $(\mathrm{HOCl})$ for $20 \mathrm{~min}$ and $10 \mathrm{~min}$, respectively. Whole Cell Ex tracts were subjected to the workflow described in A-B. Table showing total number of $\mathrm{Mal}_{-} \mathrm{PEG}_{2}$-Bio-labelled Cys sites and the number of corresponding proteins identified in each condition following the InsPEx method. Results of three independent experiments were combined for identification of the Mal-PEG 2 -Bio-labeled peptides. 
Fig. 2. Functional analysis of reversible Cys ox-PTMs induced by oxidants. A-C. Gene Ontology (GO) enrichment analysis of identified reversible Cys ox-PTMs in nonstimulated (NS) and oxidant (diamide or $\mathrm{HOCl}$ )-stimulated conditions described in Fig. $1 D$ based on the biological processes (A), molecular functions $(\mathbf{B})$ and cellular component (C). Selected host-virus interaction relevant terms are shown, and the full list of enriched terms is available in Data File S4. D-F. KEGG pathways enrichment analysis of reversible Cys ox-PTMs identified in non-stimulated (basal) and oxidant (diamide/ $\mathrm{HOCl}$ )-treated conditions described in Fig. 1D. Selected host-virus interaction relevant terms are shown in (D) and the full list of overrepresented pathways is available in Data File S5. Oxidized proteins of selected KEGG pathways enriched at basal levels (E) and in oxidant-treated cells (F) are mapped. Only Mal-PEG2-Bio-labeled Cys identified in at least two out of three independent replicates per condition were taken into account for the functional analysis.

Fig. 3. Characterization of STING Cys reversible oxidation upon HOCl and 2'3' -cGAMP stimulation. A-B. Fragment spectra of the STING peptides identified in the experiments described in Fig. 1D showing the modification of the Cys residues, C148 and $\mathrm{C}^{206}$, with Mal-PEG ${ }_{2}-$ Bio (+525.23). The fragment picks of both $\mathrm{b}$ and $\mathrm{y}$ ions are shown in the spectra in red and blue, respectively. C. U937 cells were infused with 2'3'-cGAMP at $24 \mu \mathrm{g} / \mathrm{mL}$ for the indicated times. Cells were harvested and whole cell extracts were immediately resolved by reducing (with DTT) and non-reducing (without DTT) SDS-PAGE and by SDD-AGE. Proteins were detected by immunoblot using anti-actin, anti-TBK1, antiphospho-TBK1-Ser ${ }^{172}$, anti-STING and anti-phospho-STING-Ser ${ }^{366}$ antibodies. Molecular weight $(\mathrm{kDa})$ markers are indicated on the left side of the SDS-PAGE gels. The data are representative of three independent experiments. D. U937 cells were infused with or without 2'3'-cGAMP at $24 \mu \mathrm{g} / \mathrm{mL}$ for $30 \mathrm{~min}$. WCE were subjected to the workflow described in Fig. 1A-B to identify reversible Cys ox-PTMs. Fragment spectrum of the STING peptide containing the Cys residue C206 modified with Mal- $\mathrm{PEG}_{2}$-Bio identified in the 2'3'-cGAMP stimulated condition. All MS/MS spectra were visualized with scaffold, version 4.8.4.

Fig. 4. Role of Cys ${ }^{206}$ oxidation on 2'3-cGAMP-activated STING structure and function. A. Schematic representation of the linear structure of STING showing the transmembrane domains (TM), the ligand binding pocket and the $\mathrm{C}$ terminal tail (CTT). The position of Cys $^{206}$ is indicated. B-C. Annotated structures, pdb4ef4 (B) (64) and pdb6dnk (61) (C), of STING bound to a molecule of cyclic di-GMP (in black) are shown. Top panels: structures with reduced $\mathrm{Cys}^{206}$ (Cys-SH) are shown on the left side; structures with sulfenylated $\mathrm{Cys}^{206}$ (Cys-SOH) modelized using the PyTMs plugin in PyMol are shown on the right side. Middle panels: the zone where the three amino acids are located is zoomed out. Lower panels: APBS Electrostatics plugin was used to visualize the electrostatic surface and superpose the structures containing reduced and oxidized Cys ${ }^{206}$. Cys ${ }^{206}$ (C206) is shown in blue. $\operatorname{Arg}^{281}$ (R281) and $\operatorname{Arg}^{284}$ (R284) are shown in green. Lateral chains of the three amino acids are represented in sticks. Steric van-der-Waals (vdW) hindrance (vdW clashes) are shown in red. RMSD: root-mean-square deviation of atomic positions. D-E. HEK293T cells were transfected with Flag-tagged wild-type (WT) or C206S STINGencoding plasmids or the corresponding control plasmid (empty) before stimulation with 
2'3'-cGAMP as indicated. In D, whole cell extracts were resolved by standard SDS-PAGE. Proteins were detected by immunoblot using anti-actin and anti-Flag antibodies. Molecular weight $(\mathrm{kDa})$ markers are indicated on the left side of the SDS-PAGE gels. The data are representative of three independent experiments. In E, Confocal images of cells immunostained for Flag-STING (anti-DYKDDDDK) and nuclei using 4' 6, diamido 2 phenylindole (DAPI). Representative of two independent experiments F. HEK293T cells transfected with the IFN $\beta$ promoter luciferase reporter construct together with the Flagtagged WT or C206S STING-encoding or the empty plasmid were further transfected with or without 2'3'-cGAMP at the indicated concentration. Relative luciferase activities were measured at $24 \mathrm{~h}$ post-stimulation. Mean $+/-$ SEM, $n=6$, unpaired t-test.

Fig. 5. $\mathrm{Cys}^{206}$ oxidation dampens STING activity through inhibition of Ser $^{366}$ phosphorylation and formation of inactive diS-containing polymers. A-B. HEK293T cells were transfected with the IFN $\beta$ promoter luciferase reporter construct together with the Flag-tagged WT or C206S STING-encoding plasmids or the corresponding control plasmid (empty). Cells were further transfected with 2'3'-cGAMP at $24 \mu \mathrm{g} / \mathrm{mL}$ for $1 \mathrm{~h}$ before treatment with $100 \mu \mathrm{M}$ hypochlorous acid $(\mathrm{HOCl})$ for $23 \mathrm{~h}(\mathbf{A})$ or were left untreated or stimulated with $100 \mu \mathrm{M} \mathrm{HOCl}$ for $23 \mathrm{~h}(\mathbf{B})$. Relative luciferase activities were measured. Mean +/- SEM, n=6, unpaired t-test. C-E. HEK293T cells (C and D) or A549 cells (E) were transfected with Flag-tagged WT or C206S STING-encoding plasmids or the corresponding control plasmid (empty). In $\mathbf{C}$, cells were left untreated or stimulated with $100 \mu \mathrm{M}$ HOCl. In D and E, cells were further transfected with 2'3' -cGAMP at 8 (E) or 24 (D) $\mu \mathrm{g} / \mathrm{mL}$ for $1 \mathrm{~h}$ before treatment with $100 \mu \mathrm{M} \mathrm{HOCl}$ for the indicated times. In C-D, Whole cell extracts were resolved by SDS-PAGE. In E, Whole cell extracts were resolved by reducing (with DTT) and non-reducing (without DTT) SDS-PAGE and by SDD-AGE. Proteins were detected by immunoblot using anti-actin, anti-Flag and anti-phosphoSTING-Ser ${ }^{366}$ antibodies. Molecular weight $(\mathrm{kDa})$ markers are indicated on the left side of the SDS-PAGE gels. The data are representative of three independent experiments. 
bioRxiv preprint doi: https://doi.org/10.1101/2020.03.25.008920; this version posted March 27, 2020. The copyright holder for this preprint (which was not certified by peer review) is the author/funder, who has granted bioRxiv a license to display the preprint in perpetuity. It is made available under aCC-BY 4.0 International license.

\section{Figure 1.}

A Mal-PEG 2 -Bio-based bioswitch labeling $\quad$ B

B InsPEx workllow

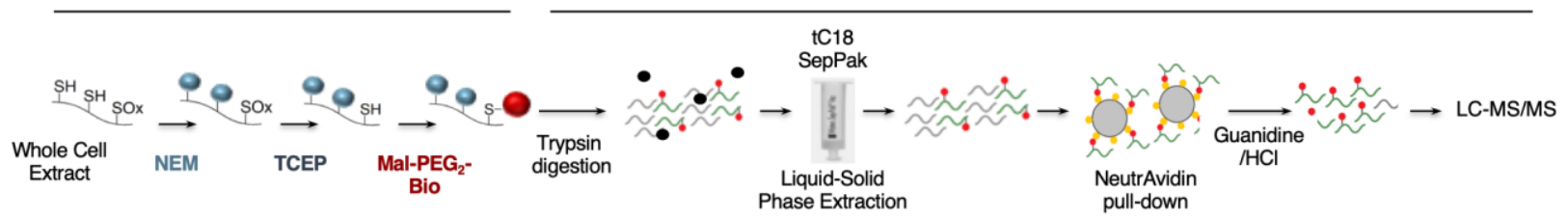

\section{C}

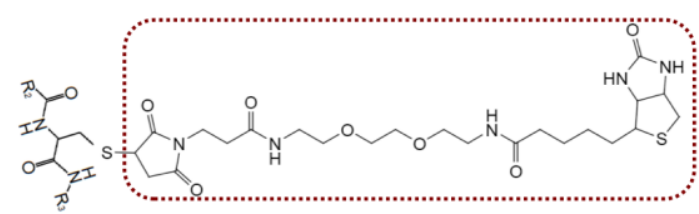

D

Cysteine

Mal-PEG - Biotin

\begin{tabular}{|ccc|}
\hline Treatment & $\begin{array}{c}\text { Cys oxPTM } \\
\text { sites }\end{array}$ & $\begin{array}{c}\text { Modified } \\
\text { proteins }\end{array}$ \\
\hline Basal & 1489 & 841 \\
\hline Diamide & 1655 & 980 \\
HOCl & 1818 & 1090 \\
Total & 2720 & 1473 \\
\hline
\end{tabular}


bioRxiv preprint doi: https://doi org/10.1101/2020.03 25.008920; this version posted March 27, 2020. The copyright holder for this preprint (which was not certified by peer review) is the author/funder, who has granted bioRxiv a license to display the preprint in perpetuity. It is made available under aCC-BY 4.0 International license.

\section{Figure 2.}

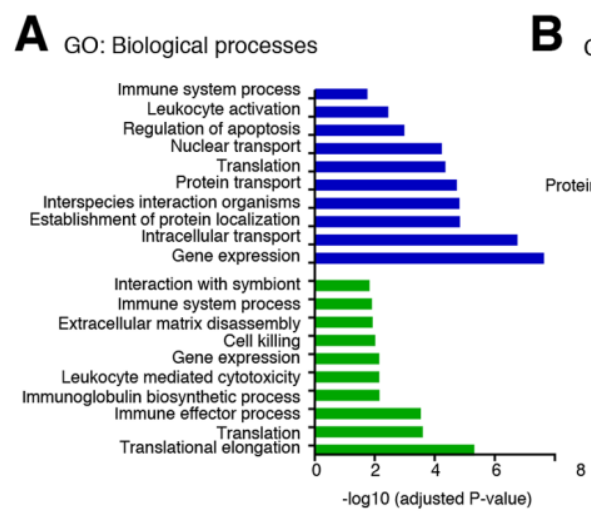

B GO: Molecular functions
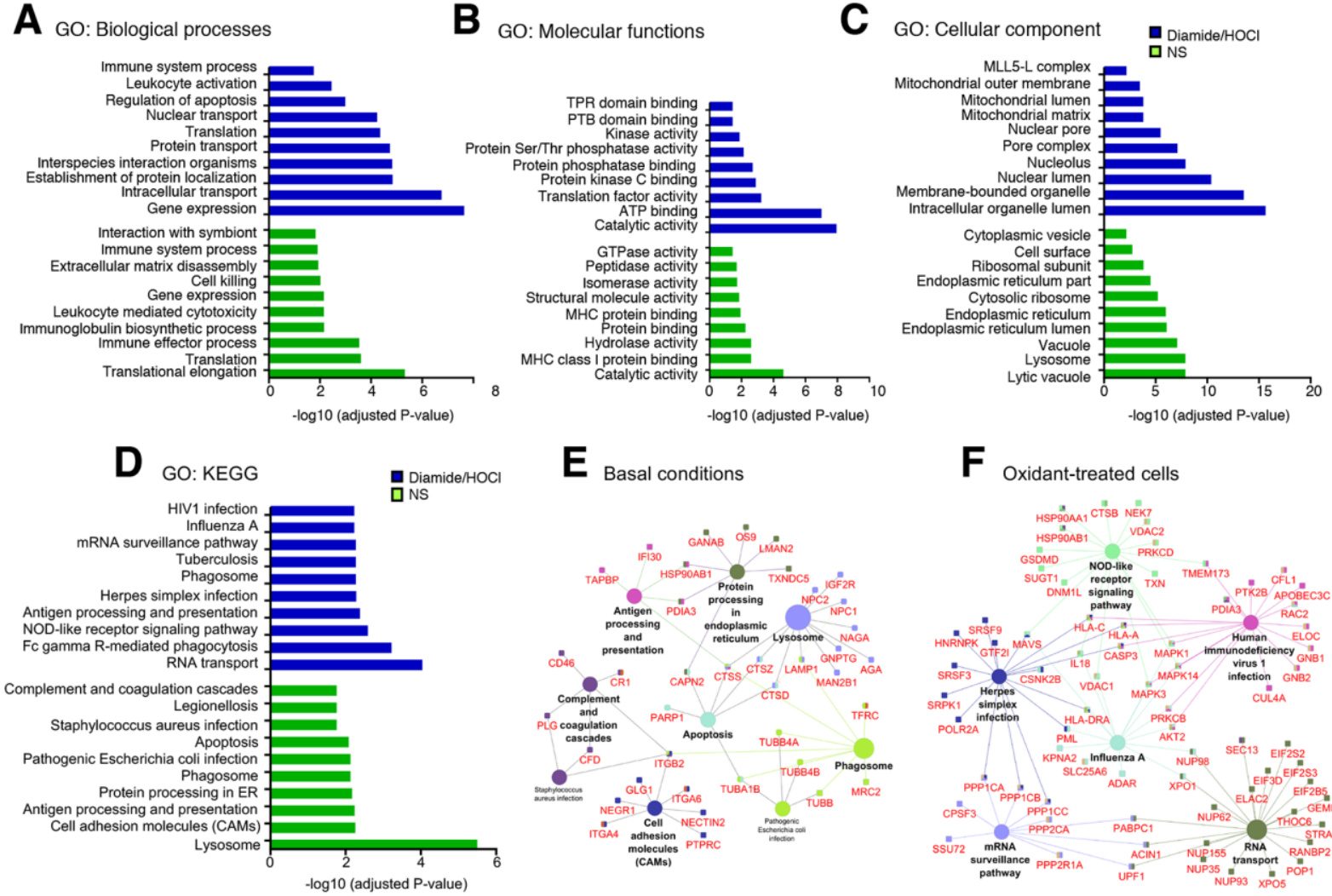

E

Basal conditions

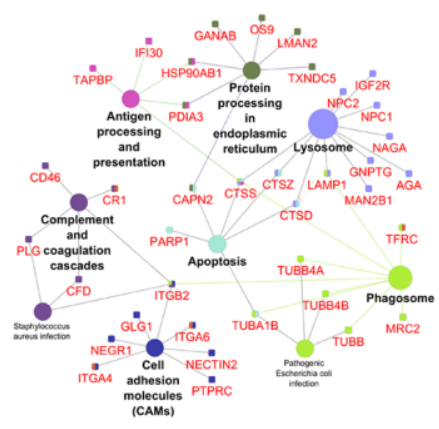

$\mathbf{F}$

Oxidant-treated cells

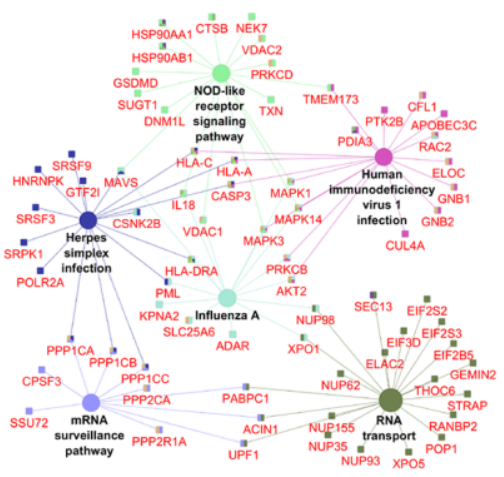


bioRxiv preprint doi: https://doi org/10.1101/2020.03.25.008920; this version posted March 27, 2020. The copyright holder for this preprint (which was not certified by peer review) is the author/funder, who has granted bioRxiv a license to display the preprint in perpetuity. It is made available under aCC-BY 4.0 International license.

\section{Figure 3.}

A

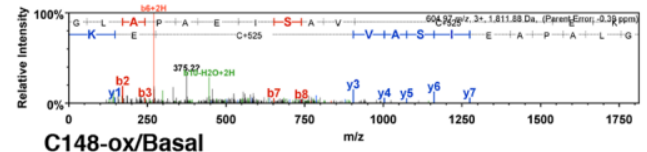

B

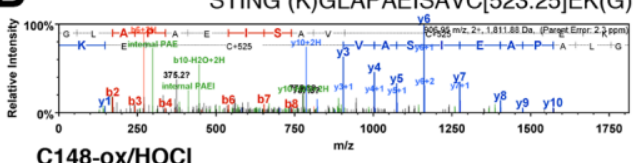
C148-ox/HOCI

STING (R)LYILLPLDC[523.25]GVPDNLSMADPNIR(F)

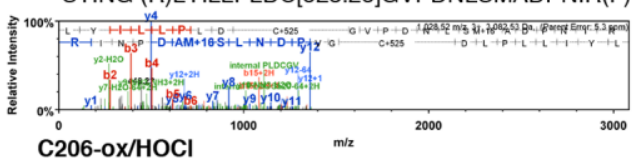

F STING (R)LYILLPLDCI523.25]GVPDNLSMADPNIR(F)

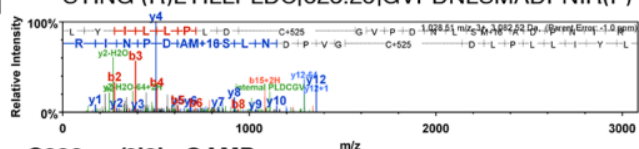
C206-ox/2'3'-cGAMP

\section{C}

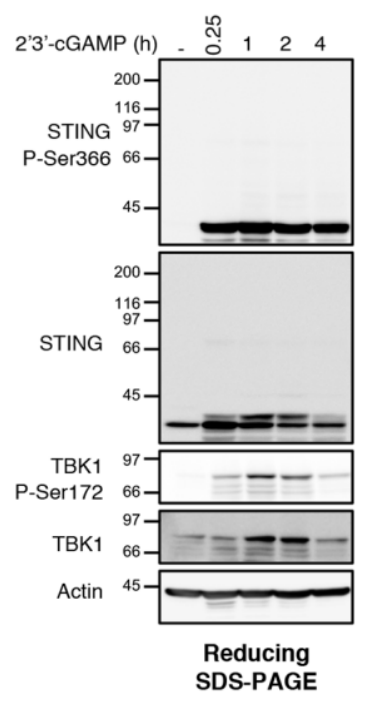

D

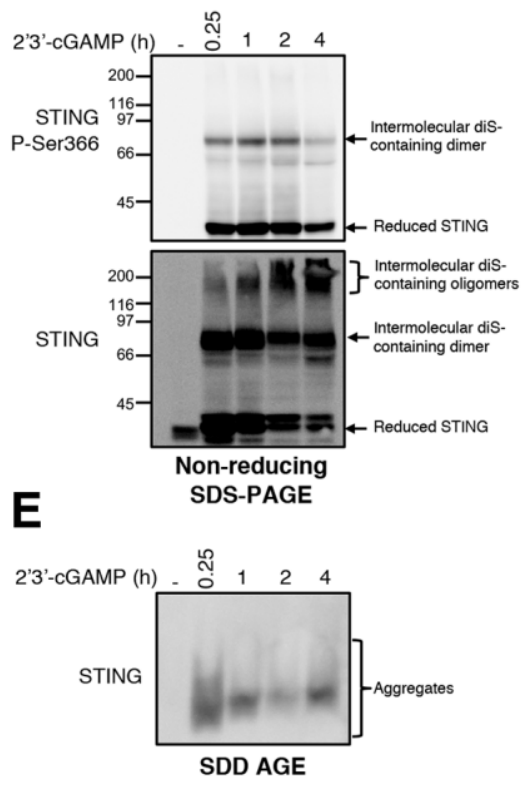


bioRxiv preprint doi: https://doi.org/10.1101/2020.03.25.008920; this version posted March 27, 2020. The copyright holder for this preprint (which was not certified by peer review) is the author/funder, who has granted bioRxiv a license to display the preprint in perpetuity. It is made available under aCC-BY 4.0 International license.

\section{Figure 4 .}

A

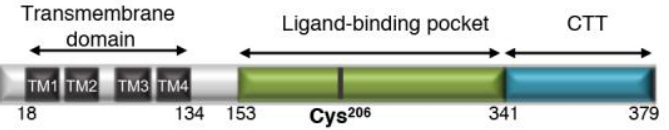

B

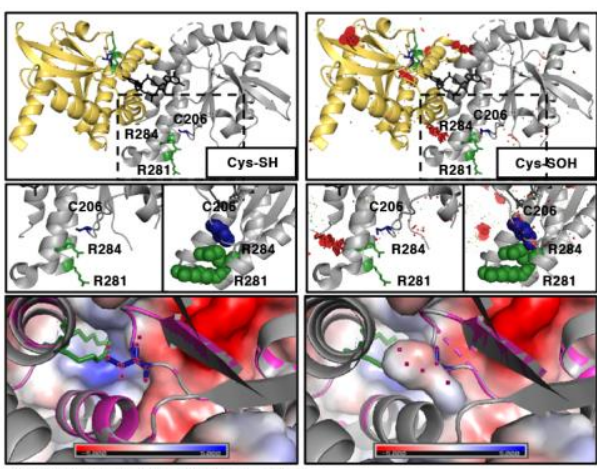

C

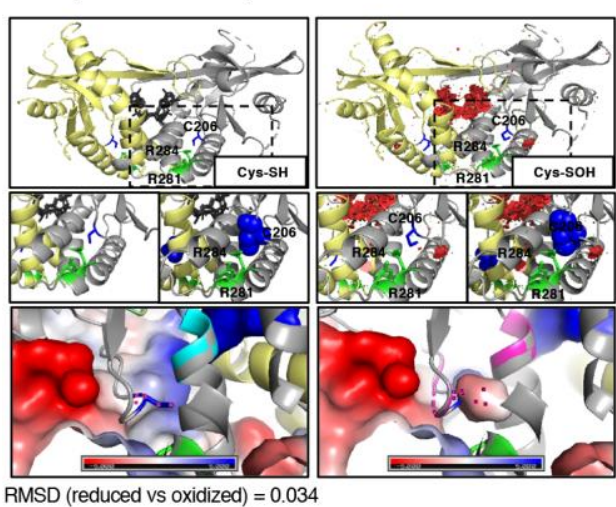

D

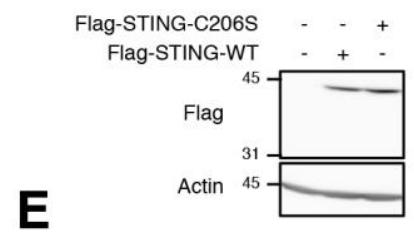

2'3'-cGAMP

WT

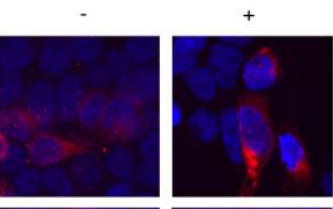

C206S
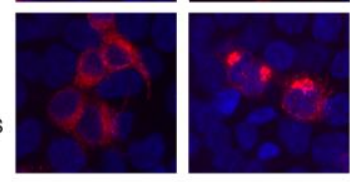

$\mathbf{F}$

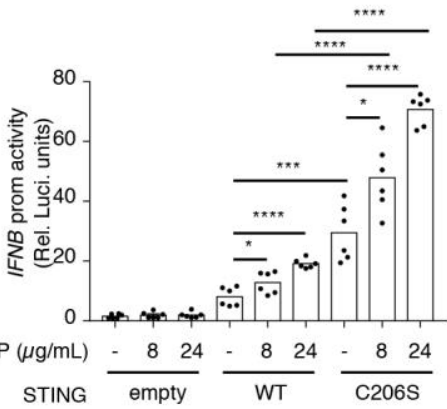


bioRxiv preprint doi: $h t t p s: / / d o i . o r g / 10.1101 / 2020.03 .25 .008920$; this version posted March 27, 2020. The copyright holder for this preprint (which was not certified by peer review) is the author/funder, who has granted bioRxiv a license to display the preprint in perpetuity. It is made available under aCC-BY 4.0 International license.

\section{Figure 5.}

A

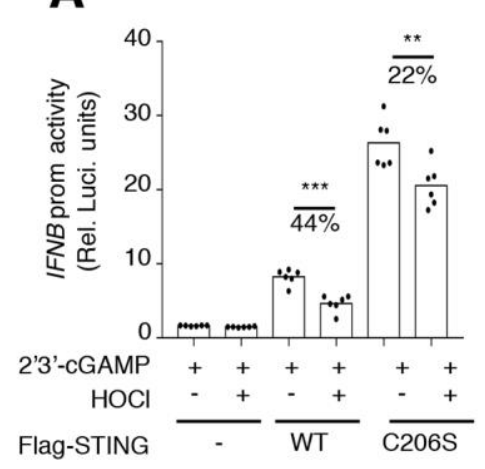

\section{C}

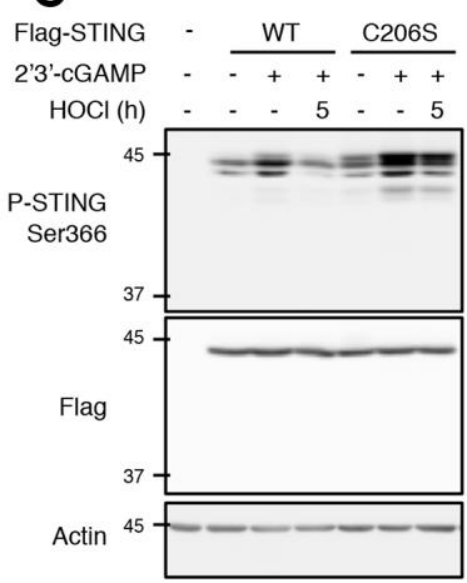

D

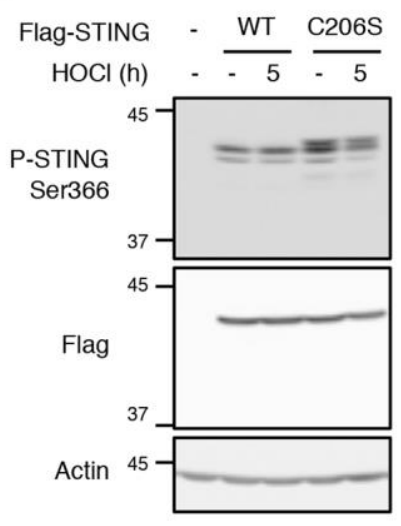

B
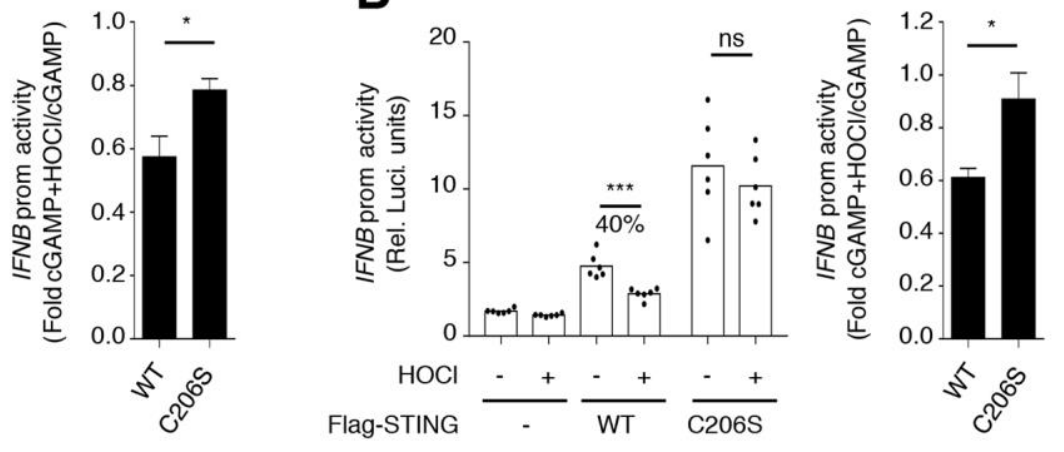

E

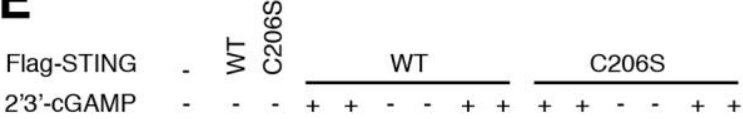

$\mathrm{HOCl}$ (time) - - - - 10,5h 10'5h - - 10'5 $10^{\prime} 5 \mathrm{~h}$

Medium (time)
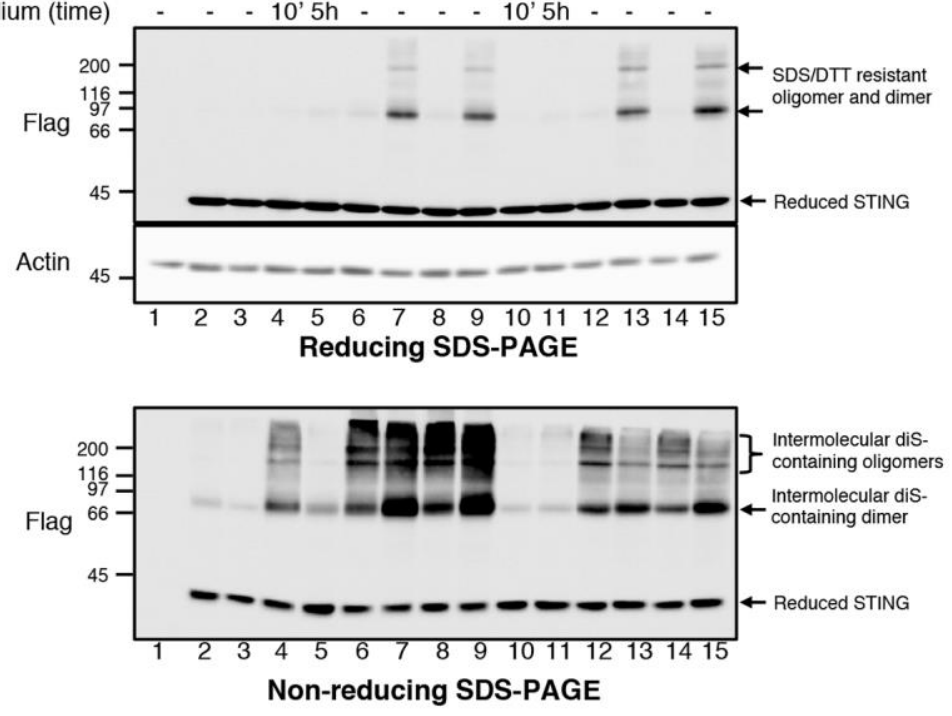

Flag

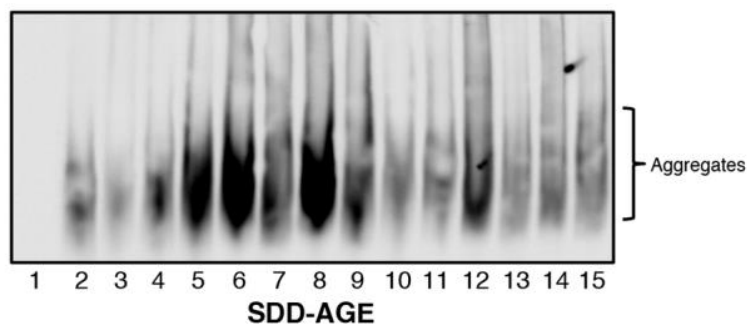




\section{Supplementary Materials:}

\section{Supplementary Materials and Methods}

\section{Plasmids}

The pcDNA3.1 Flag-STING-C148S was generated using the Quikchange Lightning SiteDirected Mutagenesis kit from Agilent (\#210518) with the 5' TCAGGCACCCCACTGTCCAATGGGAGG-3' primer. Sanger sequencing at the Génome Québec Innovation Centre (McGill University, Montréal, QC) was used to validate the mutation and STING sequence.

NeutrAvidin pull-down of Mal-PEG - -Bio-labeled proteins followed by in-gel trypsin digestion (ingel trypsinization approach, fig. S1B)

THP-1 cells (obtained from Dr. K. Gee, Queens Univ ersity, Ontario, Canada) were cultured in RPMI medium (GIBCO) supplemented with 1\% L-glutamine (GIBCO), $1 \%$ HEPES (GIBCO) and $10 \%$ Fetalclone III (FCl-III, Hyclone). Cells were subjected to stimulation with $0.5 \mathrm{mM}$ diamide for $20 \mathrm{~min}$. Proteins were subjected to $\mathrm{Mal}_{-} \mathrm{PEG}_{2}-\mathrm{Bio}$ bioswitch labeling as described in Material and Methods section. Mal-PEG ${ }_{2}$-Bio-labeled proteins were precipitated with acetone. Pellets were resuspended in HENS buffer and quantified by the BCA method. One milligram of protein was taken before addition of 2 volumes of neutralization buffer. Pull down with NeutrAvidin agarose resin was performed as described in the Material and Methods section with modifications of the elution step. Proteins were eluted with $2 X$ loading buffer composed of $50 \mathrm{mM}$ Tris/HCl pH 6.8, 4\% SDS, 8\% glycerol (BioShop), 0.0005\% bromophenol blue (Fisher Scientific) supplemented with 1.44 M $\beta$-mercaptoethanol (BME, Sigma Aldrich). Samples were heated at 100 ${ }^{\circ} \mathrm{C}$ for $10 \mathrm{~min}$ with 2 vortexing rounds to harvest all complexes. Samples were loaded on $1 \mathrm{~mm}$ SDS-PAGE gels. In order to obtain a single band containing all the proteins, the migration was stopped once the samples reached around $5 \mathrm{~mm}$ distance into the resolution gel. After staining with Coomassie Brilliant Blue R-250 Dye (BIO-RAD), the single band was cut and chopped into small pieces. In-gel trypsin (Pierce ${ }^{\mathrm{TM}}$ Trypsin Protease, MS Grade) digestion was performed as recommended by the manufacturer.

Analysis offunctional clusters in GO networks enriched in Cys ox-PTMs

Networks with overrepresented GO categories identified as described in the Material and Methods section and represented in (Fig. 2A-C) were subjected to further analysis using the greedy community-structure detection algorithm (GLay), incorporated in Cyto scape to identify functional clusters within the networks (113).

\section{Supplementary Figure legends}

Figure S1. Workflow of the bioswitch labeling strategy coupled to in gel trypsin digestion for identification of Cys ox-PTMs by MS in vivo. Supplemental figure related to Fig. 1.

A-B. Schematic of the workflow used to label reversible Cys ox-PTMs with the Mal-PEG 2 -Bio bioswitch method (A) followed by In-gel trypsinization (B). In (A), Cys-SH residues were specifically alkylated with N-ethylmaleimide (NEM). Reversibly oxidized Cys (SOx) were then 
reduced using tris(2-carboxyethyl)phosphine (TCEP) before labeling with EZ-Link Maleimide$\mathrm{PEG}_{2}$-Biotin (Mal-PEG ${ }_{2}$-Bio). In (B), Proteins from (A) were pulled down using NeutrAvidin agarose beads before loading the eluate on SDS-PAGE gel. Peptides were generated by in-gel trypsin digestion before LC-MS/MS analysis. C. Table showing the Enrichment (percentage of Mal-PEG 2 -Bio labelled peptides amongst total peptides) obtained with the InsPEx (Fig. 1A-B) and the In-gel trypsinization strategies.

Figure S2. Validation of the InsPEx bioswitch method. A. Table showing Cys ox-PTMs sites that were previously documented in the literature and were also identified in this study. Ref erences: Actin-1 (114), APE-1 (115, 116), DJ-1 (117), Grx1 (51), Trx1 (118-120), GAPDH (121), Glo1 (122), SRPK1 (123), MAPK14 (124, 125), Akt2 (126, 127). B. Individual spectra of peptides described in (A). $\mathrm{C}+125$ corresponds to a Cys alkylated with N-ethylmaleimide (NEM), thus, a Cys that was reduced in vivo. The fragment picks of both $b$ and $y$ ions are shown in the spectra in red and blue, respectively. All MS/MS spectra were visualized with scaffold, version 4.8.4.

Figure S3. Community analysis of the GO terms enriched in Cys ox-PTMs. Supplemental figure related to Fig. $2 A-C$.

Cluster visualization of the functional interaction networks generated by the fast greedy (GLay) algorithm. GLay was applied on networks in order to assemble the enriched biological processes (A), molecular functions (B) and cellular components (C). Terms enriched in non-stimulated (basal) and oxidant (diamide/HOCl)-treated conditions are shown in green and blue, respec tively. The nodes of the network correspond to each enriched GO term and the direction of the edges (arrows) refers to their level of hierarchy. Arrows go from higher to lower hierarchy levels.

Figure S4. Complete map of all enriched KEGG pathways. Supplemental figure related to Fig. $2 D-F$.

KEGG pathways enrichment analysis of identified reversible Cys ox-PTMs in non-stimulated (basal conditions) (A) and oxidant (diamide or $\mathrm{HOCl}$ )-stimulated (B) U937 cells. Oxidized proteins related with each pathway are indicated.

Figure. S5. MS identification of STING Cys oxidation sites after 2'3' -cGAMP stimulation. Supplemental figure related to Fig. $3 F$.

A. Table showing MS analysis of the identified STING peptide containing Mal-PEG 2 -Bio-labeled Cys $^{206}$ (C[525.23]) after 2'3'-cGAMP stimulation. Peptides containing Cys ${ }^{206}$ were not detected in non-stimulated cells. B. Fragmentation table showing all b (red) and y (blue) ion values for the peptide containing the labeled Cys residue shown in (A). All MS/MS spectra were visualized with scaffold, version 4.8.4.

Figure S6. STING forms intramolecular disulfide bonds independently of $\mathrm{Cys}^{\mathbf{1 4 8}}$ and $\mathrm{Cys}^{\mathbf{2 0 6}}$. A. A549 cells were transfected with WT, C206S or C148S Flag-tagged STING encoding constructs. Whole Cell Extracts were resolved by reducing (with DTT) and non-reducing (without DTT) SDS-PAGE. Proteins were detected by immunoblot using anti-tubulin and anti-Flag antibodies. Molecular weight $(\mathrm{kDa})$ markers are indicated on the left side of the SDS-PAGE gels. 
Figure S7. STING aggregates formed in response to 2' 3 ' -cGAMP are sensitive to reducing agents. U937 cells were infused with 2'3'-cGAMP at $24 \mu \mathrm{g} / \mathrm{mL}$ for the indicated times. Whole cell extracts were resolved by reducing (with DTT) and non-reducing (without DTT) SDD-AGE and by reducing SDS-PAGE. Proteins were detected by immunoblot using anti-actin, anti-STING and anti-phospho-STING-Ser ${ }^{366}$ antibodies. Molecular weight $(\mathrm{kDa})$ markers are indicated on the left side of the SDS-PAGE gels.

Figure S8. Model of STING regulation by Cys ox-PTMs. STING Cys ${ }^{148}$ is constitutively oxidized. Based on previous reports, this oxidation state is essential for STING to be activated by 2'3'-cGAMP (61). Binding of 2'3'-cGAMP triggers Ser's66 phosphorylation and activation of STING. Furthermore, Cys ${ }^{206}$ undergoes oxidation, imposing a conformational change that leads to inhibition of $\operatorname{Ser}^{366}$ phosphorylation and provokes the formation of inactive diS-containing polymers to prevent STING hyperactivation. Oxidative stress induced by $\mathrm{HOCl}$ treatment without 2'3'-cGAMP stimulation, also triggers the formation of diS-containing polymers species. 
bioRxiv preprint doi: https://doi.org/10.1101/2020.03.25.008920; this version posted March 27, 2020. The copyright holder for this preprint (which was not certified by peer review) is the author/funder, who has granted bioRxiv a license to display the preprint in perpetuity. It is made available under aCC-BY 4.0 International license.

\section{Figure S1.}

\section{A}

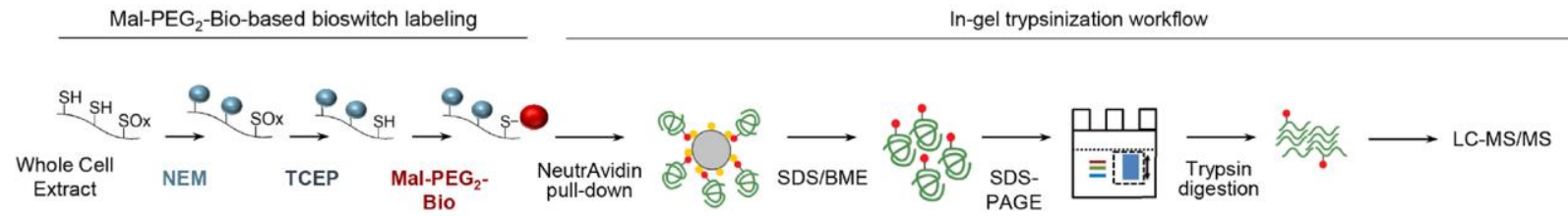

B

\begin{tabular}{|c|c|}
\hline \multicolumn{2}{|c|}{$\begin{array}{c}\text { Enrichment } \\
\text { (Mal-PEG2-Bio-labeled peptides / total } \\
\text { peptides) }\end{array}$} \\
\hline In-gel & InsPEx \\
\hline $0.5 \%$ & $83 \%$ \\
\hline
\end{tabular}


bioRxiv preprint doi: https://doi.org/10.1101/2020.03.25.008920; this version posted March 27, 2020. The copyright holder for this preprint (which was not certified by peer review) is the author/funder, who has granted bioRxiv a license to display the preprint in perpetuity. It is made available under aCC-BY 4.0 International license.

\section{Figure S2.}

A

\begin{tabular}{|c|c|c|c|c|c|c|c|}
\hline $\begin{array}{c}\text { Protein } \\
\text { accession \# }\end{array}$ & Protein name & $\begin{array}{c}\text { Observed } \\
\text { masse }(\mathrm{m} / \mathrm{z})\end{array}$ & $\begin{array}{c}\text { Charge } \\
\text { (z) }\end{array}$ & Peptide sequence & $\begin{array}{l}\text { Mascot } \\
\text { Ion } \\
\text { score }\end{array}$ & $\begin{array}{c}\text { Cys } \\
\text { position }\end{array}$ & Ref \\
\hline gil4501885 & Actin, cytoplasmic 1 & 942.68 & 4 & (R)CPEALFQPSFLGMESC[525.23]GIHETTFNSIMK(C) & 41.01 & 272 & (114) \\
\hline gil18375501 & $\begin{array}{c}\text { DNA-(apurinic or } \\
\text { apyrimidinic site) lyase } \\
\text { (APE-1) }\end{array}$ & 671.99 & 3 & (K)EEAPDILC[525.23]LQETK(C) & 15.7 & 93 & $(115,116)$ \\
\hline gil183227678 & Protein DJ-1 & 1000.47 & 2 & (R)DVVIC[525.23]PDASLEDAK(K) & 28.9 & 53 & (117) \\
\hline gil41406084 & $\begin{array}{c}\text { Glutathione peroxidase } 1 \\
\text { (Grx1) }\end{array}$ & 743.03 & 3 & (K)C[525.23]EVNGAGAHPLFAFLR(E) & 46 & 115 & (51) \\
\hline gil50592994 & Thioredoxine 1 (Trx1) & 837.38 & 2 & (K)C[525.23]MPTFQFFK(K) & 20.0 & 73 & $(118-120)$ \\
\hline gil576583519 & $\begin{array}{l}\text { Glyceraldehyde-3- } \\
\text { phosphate } \\
\text { dehydrogenase } \\
\text { (GAPDH) }\end{array}$ & 790.72 & 3 & (K)॥SNASC[525.23]TTNCLAPLAK(V) & 20.8 & 152 & (121) \\
\hline gil118402586 & $\begin{array}{l}\text { Lactoylglutathione lyase } \\
\text { (Glo1) }\end{array}$ & 1130.06 & 2 & (R)GFGHIGIAVPDVYSAC[525.23]K(R) & 50.8 & 139 & (122) \\
\hline gil47419936 & $\begin{array}{c}\text { SRSF Protein Kinase } 1 \\
\text { (SRPK1) }\end{array}$ & 940.74 & 3 & (R)AEIPC[525.23]EDEQEQEHNGPLDNK(G) & 19.4 & 455 & (123) \\
\hline gil20986512 & $\begin{array}{l}\text { Mitogen-activated } \\
\text { protein kinase } 14 \\
\text { (MAPK14) }\end{array}$ & 1157.06 & 2 & (R)DLKPSNLAVNEDC[525.23]ELK(I) & 40.2 & 162 & $(124,12-3)-3$ \\
\hline gil4502023 & $\begin{array}{c}\text { RAC-beta } \\
\text { serine/threonine-protein } \\
\text { kinase (Akt2) }\end{array}$ & 711.34 & 2 & (K)ITDFGLC[525.23]K(E) & 29.1 & 297 & $(126,12-12-1)$ \\
\hline
\end{tabular}

B
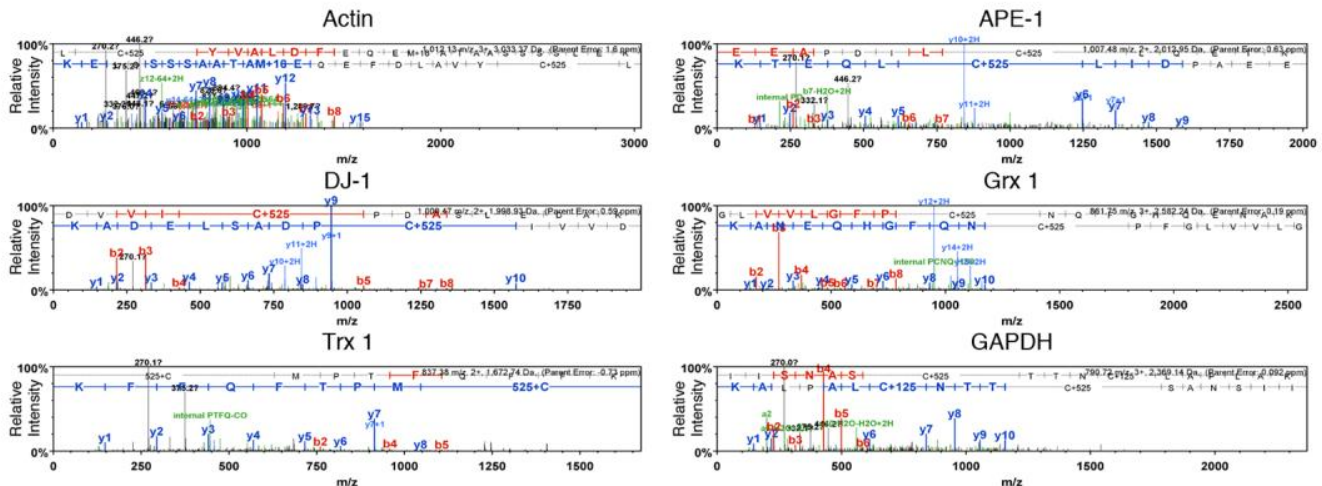

Glo 1

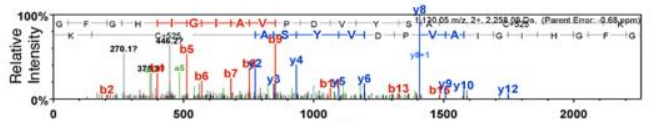

MAPK 14

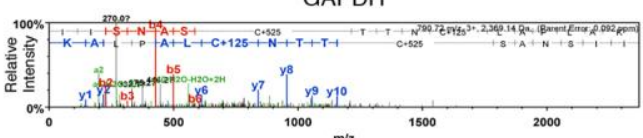

SRPK1
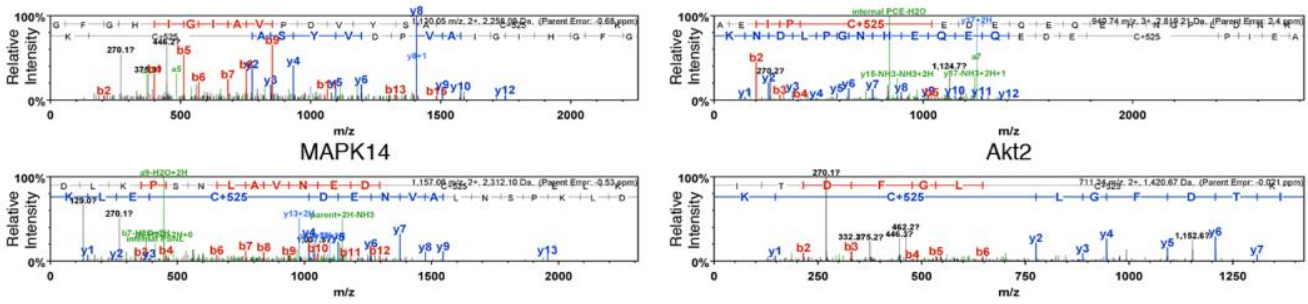
bioRxiv preprint doi: https://doi.org/10.1101/2020 03.25 .008920 ; this version posted March 27, 2020. The copyright holder for this preprint (which was not certified by peer review) is the author/funder, who has granted bioRxiv a license to display the preprint in perpetuity. It is made available under aCC-BY 4.0 International license.

\section{Figure S3.}

A

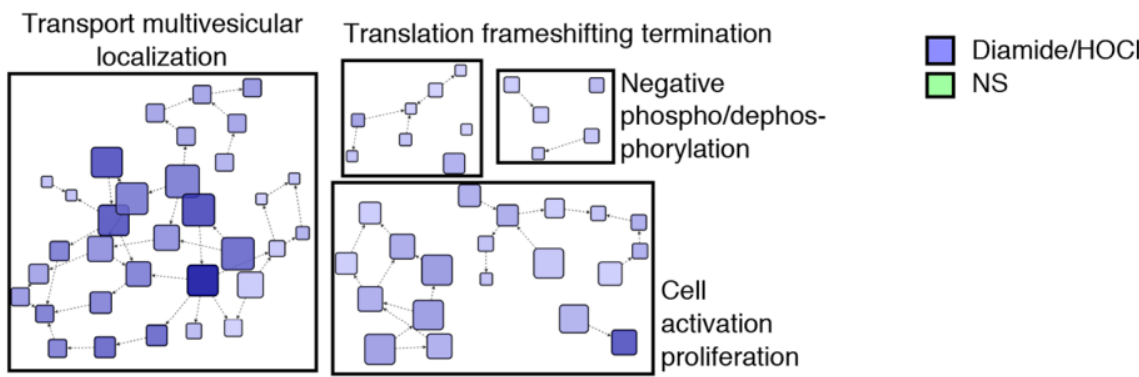

B

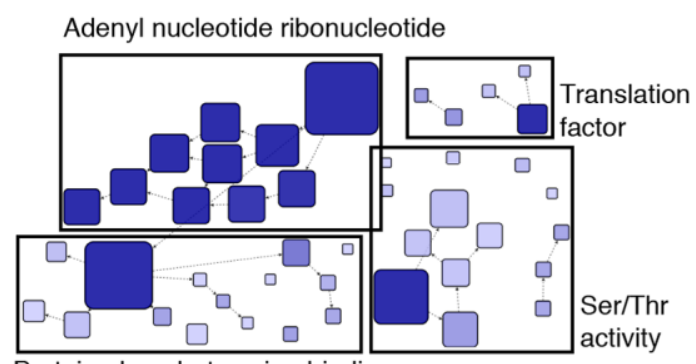

Protein phosphotyrosine binding

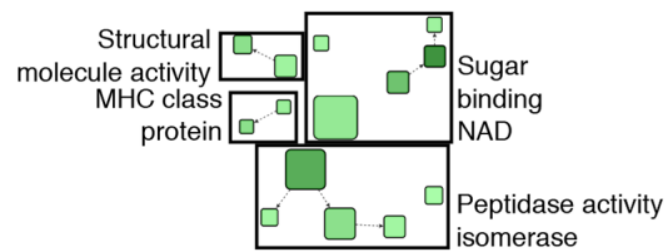

C
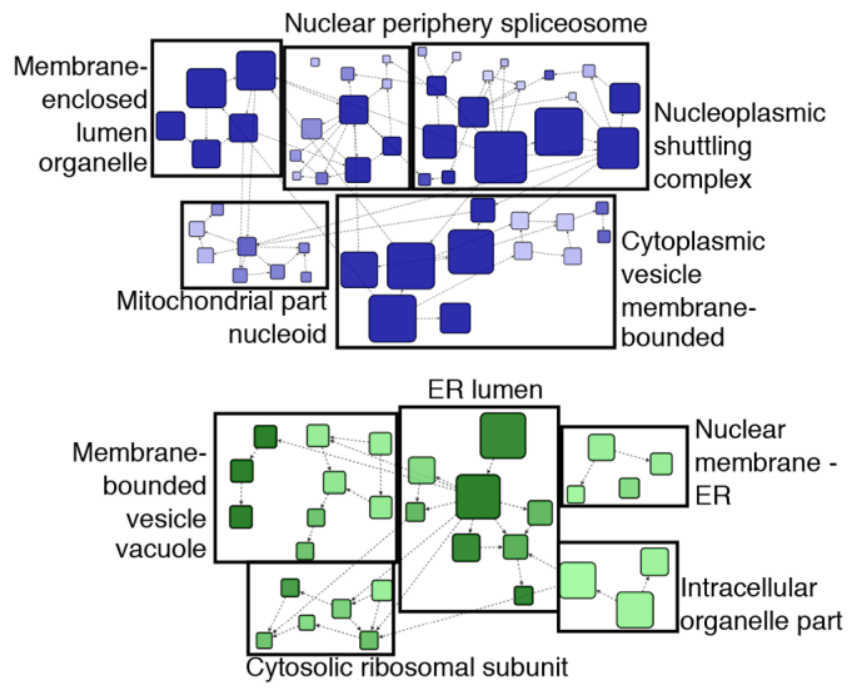
bioRxiv preprint doi: https://doi.org/10.1101/2020.03 25.008920; this version posted March 27,2020 . The copyright holder for this preprint (which was not certified by peer review) is the author/funder, who has granted bioRxiv a license to display the preprint in perpetuity. It is made available under aCC-BY 4.0 International license.

\section{Figure S4.}

A

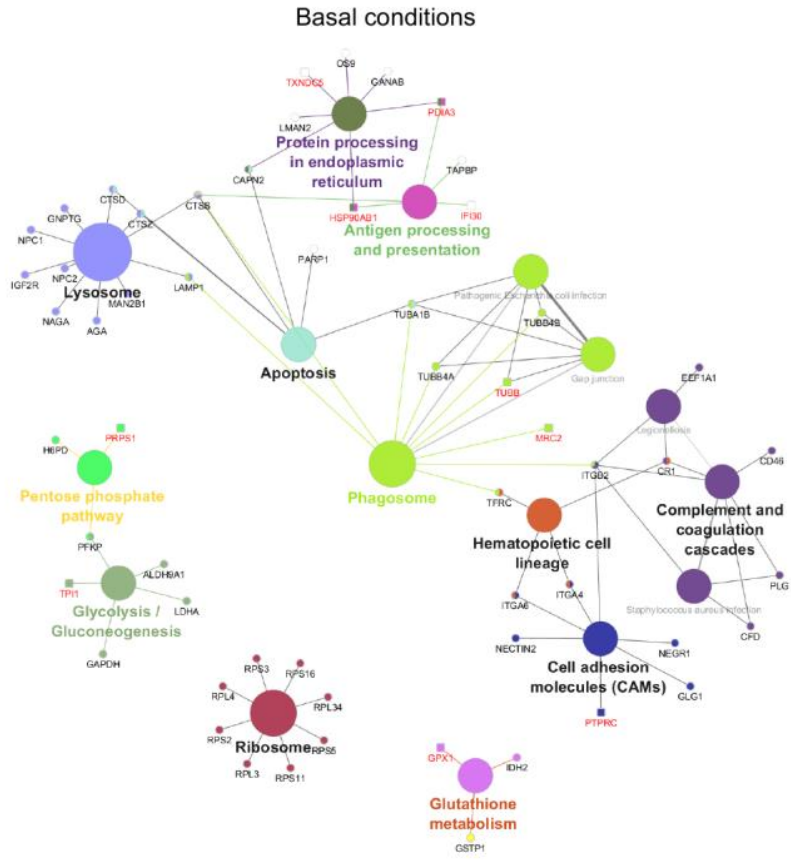

B

Oxidant-treated cells

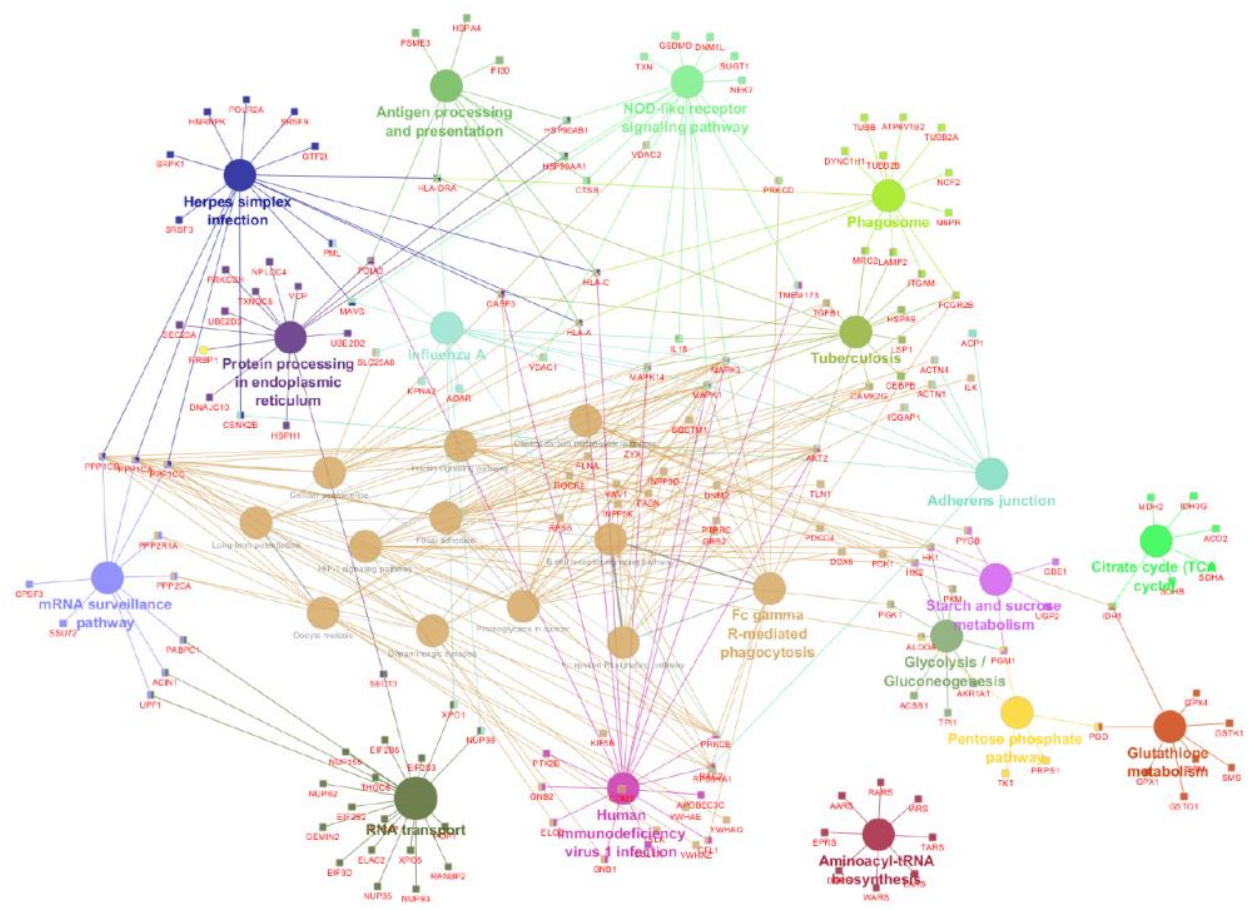


bioRxiv preprint doi: https://doi.org/10.1101/2020.03.25.008920; this version posted March 27, 2020. The copyright holder for this preprint (which was not certified by peer review) is the author/funder, who has granted bioRxiv a license to display the preprint in perpetuity. It is made available under aCC-BY 4.0 International license.

Figure S5.

A

\begin{tabular}{|c|c|c|c|c|c|c|}
\hline $\begin{array}{c}\text { Protein } \\
\text { accession \# }\end{array}$ & Protein name & $\begin{array}{c}\text { Observed } \\
\text { masse }(\mathbf{m} / \mathbf{z})\end{array}$ & $\begin{array}{c}\text { Charge } \\
(\mathbf{z})\end{array}$ & $\begin{array}{c}\text { Mascot } \\
\text { lon score }\end{array}$ & $\begin{array}{c}\text { Cys } \\
\text { position }\end{array}$ \\
\hline gil38093659 & $\begin{array}{c}\text { Stimulator of interferon } \\
\text { genes }\end{array}$ & 1023.18 & 3 & (R)LYILLPLDC[525.23]GVPDNLSMADPNIR(F) & 24.5 & 206 \\
\hline
\end{tabular}

B

\begin{tabular}{|c|c|c|c|c|c|c|c|c|c|c|}
\hline B & B Ions & $\mathrm{B}+2 \mathrm{H}$ & $\mathrm{B}-\mathrm{NH} 3$ & $\mathrm{~B}+\mathrm{H} 2 \mathrm{O}$ & AA & $Y$ Ions & $\mathrm{Y}+2 \mathrm{H}$ & $\mathrm{Y}-\mathrm{NH} 3$ & $\mathrm{Y}+\mathrm{H} 2 \mathrm{O}$ & $Y$ \\
\hline 1 & 114.1 & 57.5 & & & L & $3,067.5$ & 1.534 .3 & $3,050.5$ & 3.049 .5 & 23 \\
\hline 2 & 277.2 & 139.1 & & 259.1 & $\mathbf{Y}$ & $2,954.4$ & 1.477 .7 & $2,937.4$ & $2,936.4$ & 22 \\
\hline 3 & 390.2 & 195.6 & & 372.2 & I & 2.791 .4 & 1.396 .2 & $2,774.4$ & $2,773.4$ & 21 \\
\hline 4 & 503.3 & 252.2 & & 485.3 & L & 2.678 .3 & $1,339.7$ & $2,661.3$ & 2.660 .3 & 20 \\
\hline 5 & 616.4 & 308.7 & & 598.4 & L & $2,565.2$ & $1,283.1$ & $2,548.2$ & $2,547.2$ & 19 \\
\hline 6 & 713.5 & 357.2 & & 695.4 & $\mathbf{P}$ & $2,452.1$ & 1.226 .6 & $2,435.1$ & $2,434.1$ & 18 \\
\hline 7 & 826.5 & 413.8 & & 808.5 & L & $2,355.1$ & 1.178 .0 & $2,338.1$ & $2,337.1$ & 17 \\
\hline 8 & 941.6 & 471.3 & & 923.6 & D & 2.242 .0 & 1.121 .5 & 2.225 .0 & 2.224 .0 & 16 \\
\hline 9 & 1.569 .8 & 785.4 & & 1.551 .8 & $C+525$ & $2,127.0$ & 1.064 .0 & 2.109 .9 & $2,109.0$ & 15 \\
\hline 10 & $1,626.8$ & 813.9 & & $1,608.8$ & G & 1.498 .7 & 749.9 & 1.481 .7 & $1,480.7$ & 14 \\
\hline 11 & $1,725.9$ & 863.5 & & 1.707 .9 & v & $1,441.7$ & 721.4 & 1.424 .7 & $1,423.7$ & 13 \\
\hline 12 & 1.822 .9 & 912.0 & & 1.804 .9 & $\mathbf{P}$ & 1.342 .6 & 671.8 & 1.325 .6 & 1.324 .6 & 12 \\
\hline 13 & 1.938 .0 & 969.5 & & 1.920 .0 & D & 1.245 .6 & 623.3 & 1.228 .6 & 1.227 .6 & 11 \\
\hline 14 & 2.052 .0 & 1.026 .5 & 5.0 & 2.034 .0 & $N$ & 1.130 .6 & 565.8 & 13.5 & 2.6 & 10 \\
\hline 15 & 2.165 .1 & 1.083 .1 & 2.148 .1 & $2,147.1$ & L & $1,016.5$ & 508.8 & 999.5 & 998.5 & 9 \\
\hline 16 & 2.252 .1 & 1.126 .6 & 2.235 .1 & 2.234 .1 & 5 & 903.4 & 452.2 & 886.4 & 885.4 & 8 \\
\hline 17 & $2,383.2$ & 1.192 .1 & $2,366.1$ & $2,365.2$ & $M$ & 816.4 & 408.7 & 799.4 & 798.4 & 7 \\
\hline 18 & 2.454 .2 & 1.227 .6 & $2,437.2$ & 2.436 .2 & A & 685.4 & 343.2 & 668.3 & 667.4 & 6 \\
\hline 19 & $2,569.2$ & 1.285 .1 & 2.552 .2 & 2.551 .2 & D & 614.3 & 307.7 & 597.3 & 596.3 & 5 \\
\hline 20 & $2,666.3$ & 1.333 .6 & 2.649 .3 & 2.648 .3 & $\mathbf{P}$ & 499.3 & 250.2 & 482.3 & 481.3 & 4 \\
\hline 21 & 2.780 .3 & 1.390 .7 & 2.763 .3 & 2.762 .3 & N & 402.2 & 201.6 & 385.2 & 384.2 & 3 \\
\hline 22 & 2.893 .4 & $1,447.2$ & $2,876.4$ & $2,875.4$ & I & 288.2 & 144.6 & 271.2 & 270.2 & 2 \\
\hline 23 & $3,067.5$ & 1.534 .3 & $3,050.5$ & $3,049.5$ & $\mathbf{R}$ & 175.1 & 88.1 & 158.1 & & 1 \\
\hline
\end{tabular}


bioRxiv preprint doi: https://doi.org/10.1101/2020.03.25.008920; this version posted March 27, 2020. The copyright holder for this preprint (which was not certified by peer review) is the author/funder, who has granted bioRxiv a license to display the preprint in perpetuity. It is made available under aCC-BY 4.0 International license.

\section{Figure S6.}

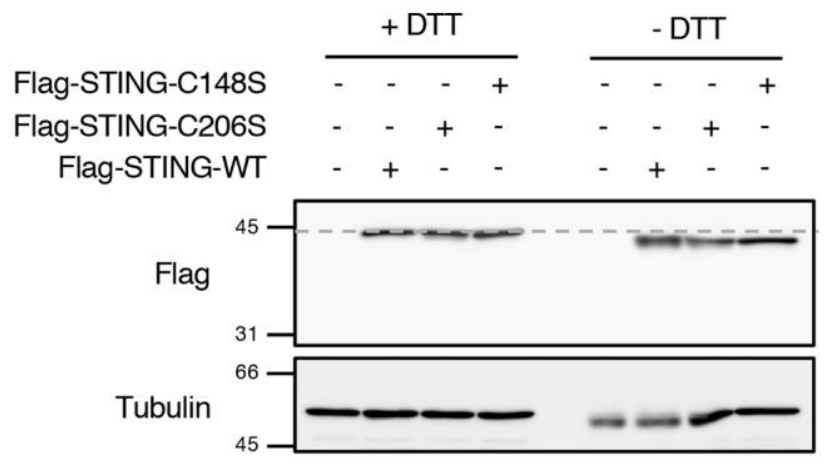


bioRxiv preprint doi: https://doi.org/10.1101/2020.03.25.008920; this version posted March 27, 2020. The copyright holder for this preprint (which was not certified by peer review) is the author/funder, who has granted bioRxiv a license to display the preprint in perpetuity. It is made available under aCC-BY 4.0 International license.

\section{Figure S7.}

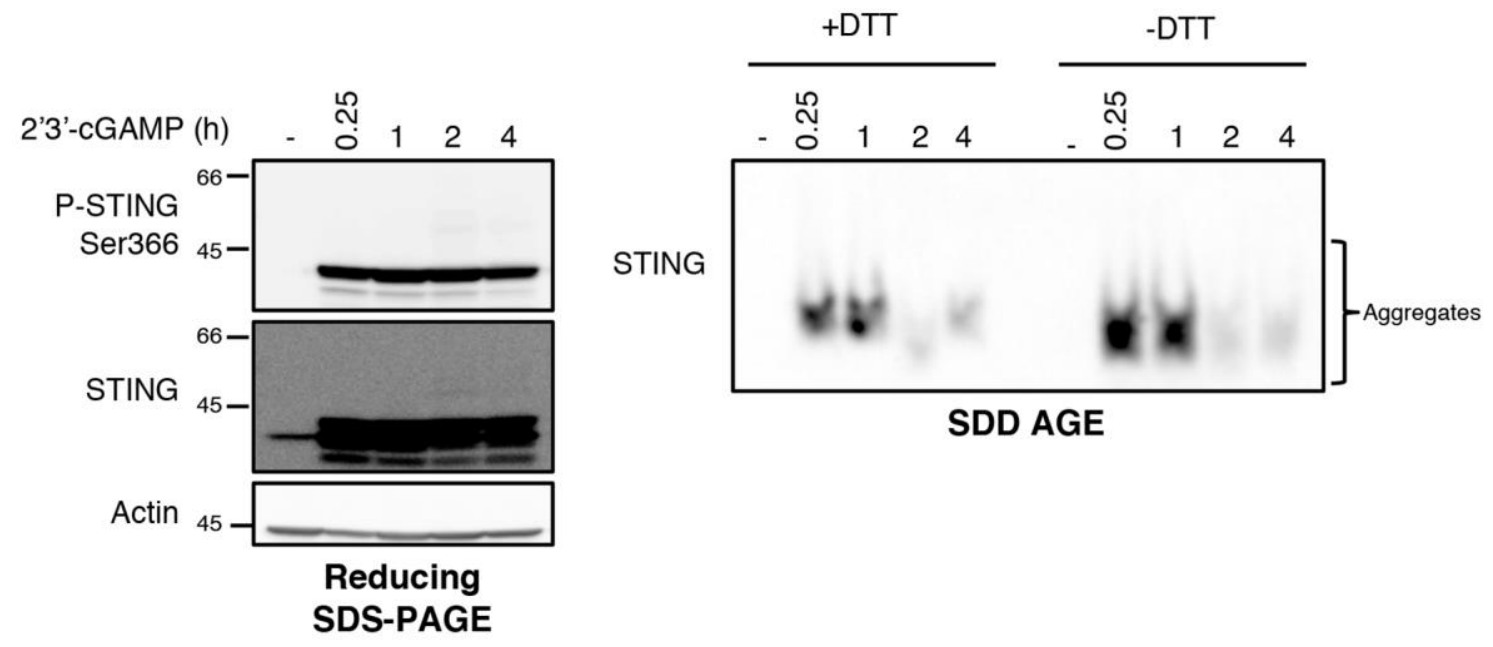


bioRxiv preprint doi: https://doi.org/10.1101/2020.03.25.008920; this version posted March 27, 2020. The copyright holder for this preprint (which was not certified by peer review) is the author/funder, who has granted bioRxiv a license to display the preprint in perpetuity. It is made available under aCC-BY 4.0 International license.

\section{Figure S8.}

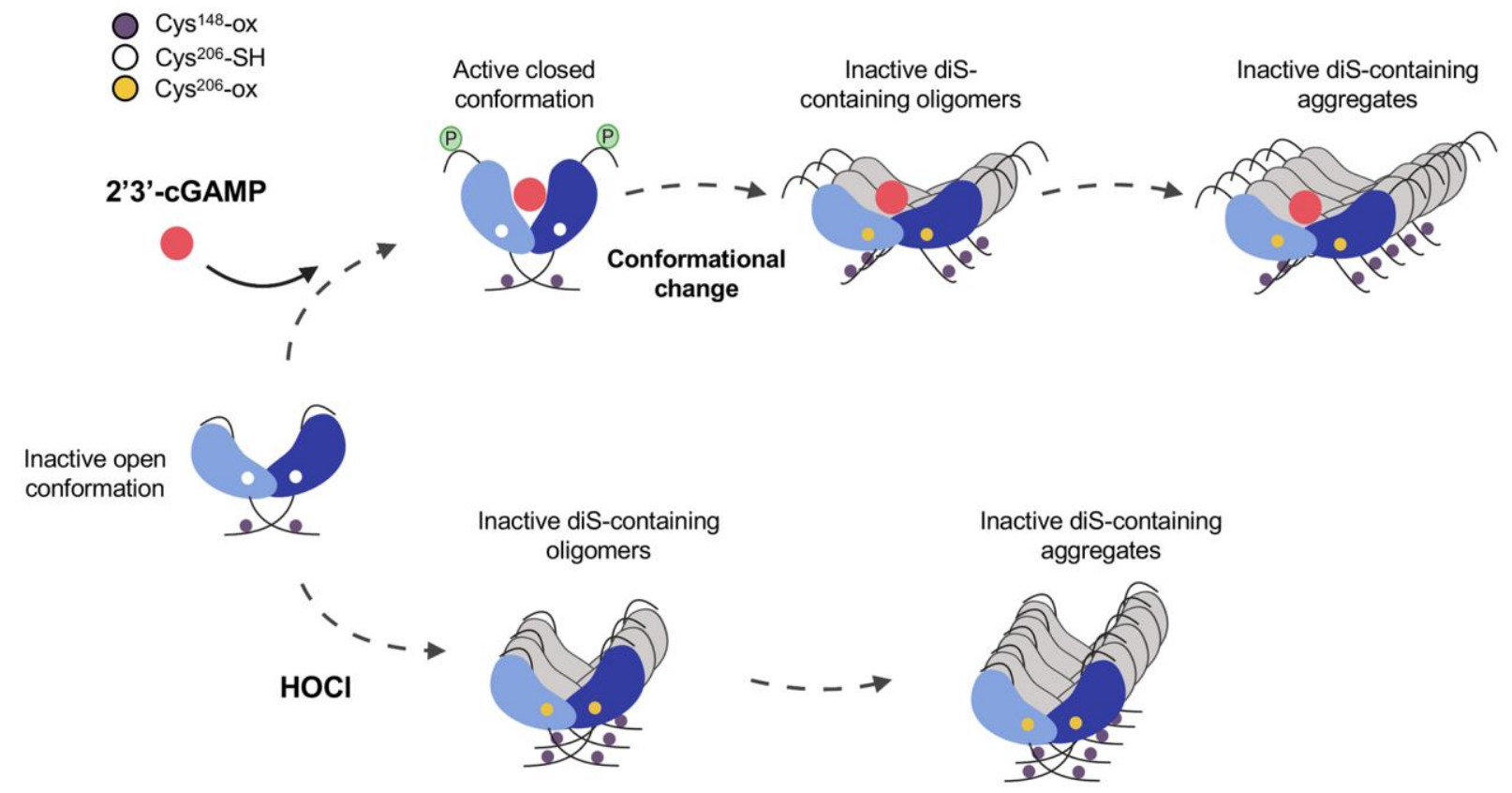

